\title{
Connexin43 mediates NF-KB signalling activation induced by high glucose in GMCs: involvement of $\mathrm{c}-\mathrm{Src}$
}

\author{
Xi Xie ${ }^{1,2}$, Tian Lan ${ }^{3}$, Xiuting Chang ${ }^{1}$, Kaipeng Huang ${ }^{1}$, Juan Huang ${ }^{1}$, Shaogui Wang ${ }^{1}$, Cheng Chen ${ }^{1}$, Xiaoyan Shen ${ }^{1}$, \\ Peiqing Liu ${ }^{1}$ and Heqing Huang ${ }^{1 *}$
}

\begin{abstract}
Background: Nuclear factor kappa-B (NF-kB) signalling plays an important role in diabetic nephropathy. Altered expression of connexin43 (Cx43) has been found in kidneys of diabetic animals. The aim of the current study was to investigate the role of $\mathrm{C} \times 43$ in the activation of NF-KB induced by high glucose in glomerular mesangial cells (GMCs) and to determine whether c-Src is involved in this process.

Results: We found that downregulation of Cx43 expression induced by high glucose activated NF-KB in GMCs. Orverexpression of $\mathrm{C} \times 43$ attenuated NF-kB p65 nuclear translocation induced by high glucose. High glucose inhibited the interaction between $\mathrm{Cx} 43$ and c-Src, and enhanced the interaction between c-Src and IkB-a. PP2, a c-Src inhibitor, also inhibited the tyrosine phosphorylation of IKB-a and NF-KB p65 nuclear translocation induced by high glucose. Furthermore, overexpression of $\mathrm{C} \times 43$ or inhibition of c-Src attenuated the upregulation of intercellular adhesion molecule-1 (ICAM-1), transforming growth factor-beta 1 (TGF- $\beta 1$ ) and fibronectin (FN) expression induced by high glucose.

Conclusions: In conclusion, downregulation of Cx43 in GMCs induced by high glucose activates c-Src, which in turn promotes interaction between c-Src and IKB- $\alpha$ and contributes to NF-KB activation in GMCs, leading to renal inflammation.
\end{abstract}

Keywords: Connexin43, NF-kB signalling, c-Src, Diabetic nephropathy, Inflammation, Fibronectin

\section{Background}

Diabetic nephropathy (DN) is one of the most serious microvascular complications of diabetes and the leading cause of end-stage renal failure. DN is characterized by excessive deposition of extracellular matrix (ECM) proteins, such as fibronectin (FN) and collagen, in the glomerulus and renal tubulointerstitium [1,2]. Hyperglycemia is the primary pathogenetic factor for diabetic renal diseases. In recent years, inflammation has emerged as a key pathophysiological mechanism of DN. Chronic low-grade inflammation and activation of the innate immune system play significant roles in the pathogenesis of $\mathrm{DN}[3,4]$. In diabetes, activated nuclear factor- $\mathrm{kB}(\mathrm{NF}-\mathrm{\kappa B})$ translocates

\footnotetext{
* Correspondence: huangheq@mail.sysu.edu.cn

'Laboratory of Pharmacology \& Toxicology, School of Pharmaceutical

Sciences, Sun Yat-sen University, Guangzhou 510006, China

Full list of author information is available at the end of the article
}

into the nucleus and triggers the expression of its target genes, including intercellular adhesion molecule-1 (ICAM1 ) and transforming growth factor-beta 1 (TGF- $\beta 1$ ). These genes cause persistent and enhanced inflammation, leading to excessive FN production and ECM accumulation. Consequently, the pathogenesis of glomerular sclerosis and tubulointerstitial fibrosis are accelerated [5-7]. However, the mechanisms by which high glucose activates NF- $\mathrm{kB}$ in $\mathrm{DN}$ remain to be explored.

Gap junctional intercellular communication (GJIC) relies on the presence of intercellular protein channels that span the lipid bilayers of contiguous cells, allowing them to directly exchange ions and small molecules [8]. In vertebrates, gap junctions are comprised of a multi-gene family called connexins, among which connexin $43(\mathrm{Cx} 43)$ is expressed the most extensively [9]. Glomerular mesangial cells (GMCs) are highly coupled by Cx43-containing gap 


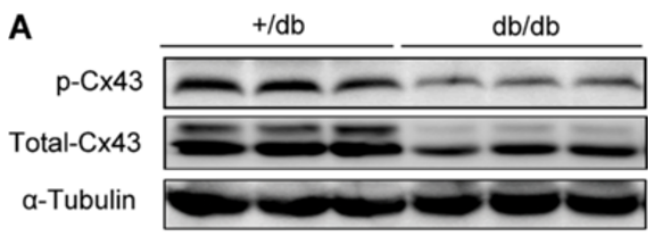

$\square p-C \times 43=C \times 43$
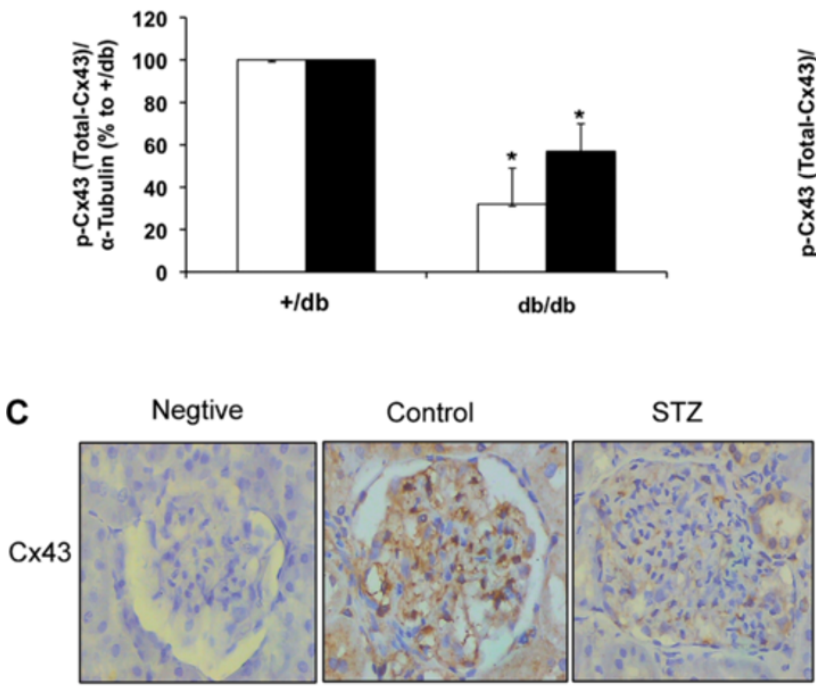

D

a

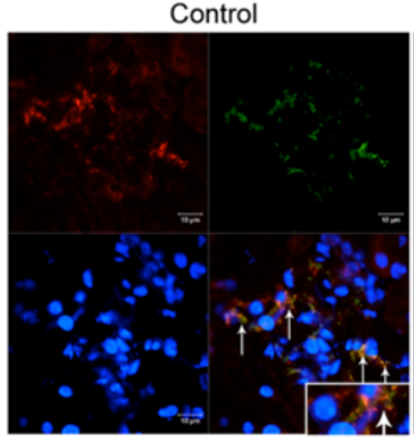

b

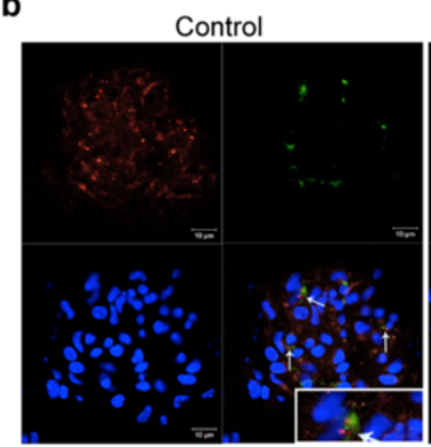

STZ

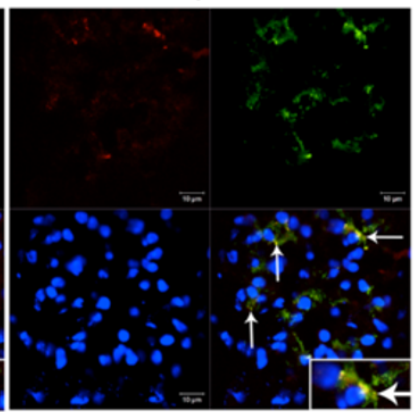

STZ

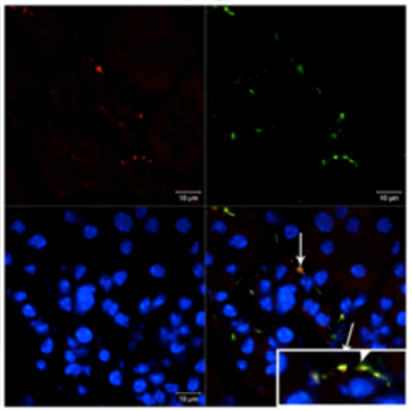

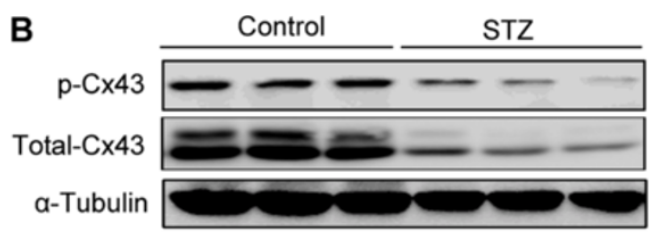

$\square \mathrm{p}-\mathrm{C} \times 43=\mathrm{Cx} 43$

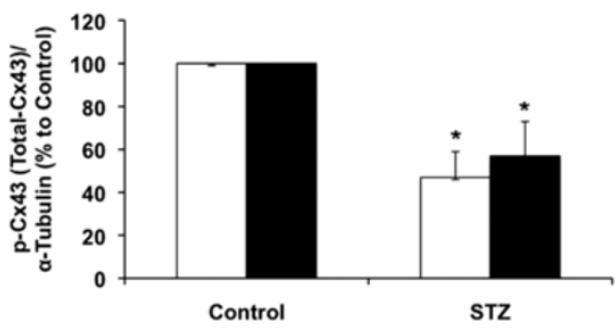

E

NG

HG

Phase contrast

Cx43

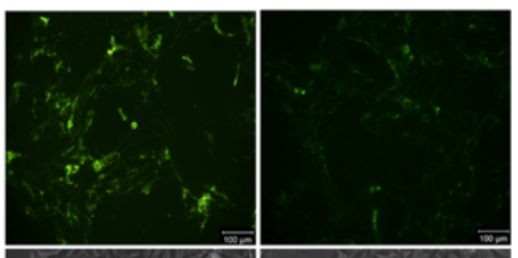

Overlay
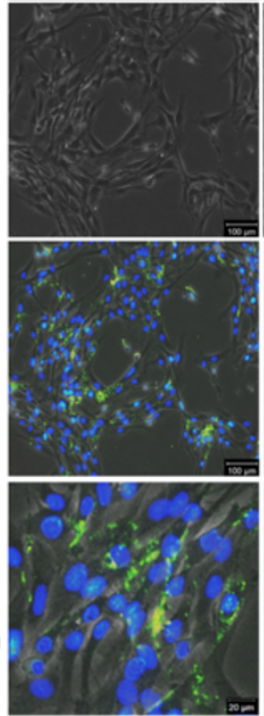

Magnification

$\mathbf{F}$

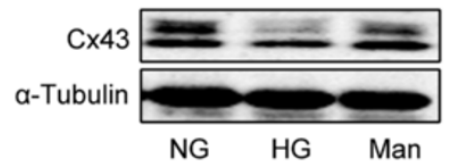

Figure 1 (See legend on next page.) 
(See figure on previous page.)

Figure 1 Cx43 expression is decreased in diabetic kidneys and high glucose-induced GMCs. (A, B) Phosphorylation of Cx43 and total CX43 expression in kidneys of $d b / d b$ mice and STZ-induced diabetic rats were detected by immunoblotting. (C) Cx43 expression was measured by immunohistochemistry in kidneys of STZ-induced rats. Staining without the CX43 antibody was used as a negative control. (D) Images of frozen kidney sections from STZ-induced diabetic rats stained doubly with anti-Cx43 antibody and anti-Thy-1.1 antibody (a) or anti-RECA-1 antibody (b). Red fluorescence indicates Cx43. Green fluorescence indicates thy-1.1 (a) or RECA-1 (b). Blue fluorescence indicates nuclei. Scale bar represents $10 \mu \mathrm{m}$ (magnification 400X). (E) GMCs were cultured in DMEM containing normal glucose (NG; $5.5 \mathrm{mmol} / \mathrm{L}$ ) and serum starved for $16 \mathrm{~h}$ before exposure to high glucose (HG; $30 \mathrm{mmol} / \mathrm{L})$. Cx43 expression was measured by immunofluorescence after 30 min of HG stimulation (upper panel). Phase contrast views are also shown (second panel). Green fluorescence indicates Cx43. Scale bar represents $100 \mu \mathrm{m}$ (magnification 100x). Scale bar represents $20 \mu \mathrm{m}$ in magnification views (lower panel, magnification 400X). (F) Cx43 was measured by immunoblotting after treatment for $30 \mathrm{~min}$ with high glucose $(30 \mathrm{mmol} / \mathrm{L})$. Mannitol (30 mmol/L) was used as an osmotic control. Experiments were performed at least three times with similar results. ${ }^{*} P<0.05$ vs. control group.

junctions. Expression level of Cx43 has been reported to parallel the function of GJIC [10,11]. Several studies have demonstrated that $\mathrm{Cx} 43$ is involved in the pathogenesis of DN. For example, protein level of $\mathrm{Cx} 43$ has been reported to decrease in the kidneys of diabetic patients and animals. Altered gap junctional communication, including abnormality in $\mathrm{Cx} 43$, plays a role in altered renal auto-regulation in diabetes [12,13]. Decreased Cx43 is also found in high glucose-treated GMCs. Downregulation of Cx43 induced by high glucose results in senescence and hypertrophy of GMCs [11,14].

The intracellular carboxy tail of $\mathrm{Cx} 43$ (Cx43CT) interacts with numerous signalling and scaffolding proteins and thereby regulates cell functions such as cell adhesion, migration, and proliferation $[8,15]$. Cx43CT interacts with c-Src, a non-receptor tyrosine kinase that can regulate cell proliferation. Activated c-Src phosphorylates $\mathrm{Cx} 43$ on the critical tyrosine residues, Tyr247 and Tyr265, and reduces intercellular communication and Cx43 internalisation $[16,17]$. High glucose-induced protein kinase $\mathrm{C}$ and c-Src-dependent big mitogen-activated protein kinase 1 activation are reportedly involved in the pathogenesis of DN [18]. A recent study has shown that activation of c-Src mediates platelet-derived growth factor-induced smad1 phosphorylation and contributes to the progression of glomerulosclerosis in glomerulonephritis [19].

As mentioned above, decreased Cx43 and activated cSrc, which interacts with $\mathrm{Cx} 43 \mathrm{CT}$, are associated with the pathogenesis of $\mathrm{DN}$. Here, we investigated the role of $\mathrm{Cx} 43$ in the activation of NF-kB induced by high glucose in GMCs to determine whether c-Src is involved in this process. In addition, we elucidated the molecular mechanism linking these cellular events.

\section{Results}

Cx43 expression is downregulated and c-Src activity is enhanced in the kidneys of diabetic animals and GMCs exposed to high glucose

We examined expression of $\mathrm{Cx} 43$ in diabetic kidneys of diabetic $(d b / d b)$ mice and STZ-induced diabetic rats by immunoblotting. Compared with normal animals, phosphorylated form of $\mathrm{Cx} 43$ and total $\mathrm{Cx} 43$ protein levels were reduced in the kidneys of both diabetic animals $(P<0.05$; Figures $1 \mathrm{~A}$ and $\mathrm{B})$. Immunohistological staining also showed lower positive expression of $\mathrm{Cx} 43$ in the kidneys of STZ-induced diabetic rats compared with normal rats (Figure 1C). Double immunolabeling of frozen kidney sections showed that $\mathrm{Cx} 43$ is expressed in both mesangial and endothelial cells. Furthermore, downregulation of Cx43 was observed in both cell types in the kidneys of STZinduced diabetic rats (Figure 1D). High glucose $(30 \mathrm{mmol} / \mathrm{L})$ treatment for 30 min decreased Cx43 expression in GMCs, whereas mannitol $(30 \mathrm{mmol} / \mathrm{L})$ treatment for the same duration exhibited no such effect (Figure 1F). Immunofluorescence results confirmed the decrease in Cx43 expression in GMCs cultured in $30 \mathrm{mM}$ glucose (Figure 1E). c-Src Y416 phosphorylation was found to be upregulated in the kidneys of $d b / d b$ mice and STZ-induced diabetic rats, and the total amount of c-Src remained constant throughout the experiment $(P<0.05$; Figures $2 \mathrm{~A}$ and $\mathrm{B})$. In addition, high glucose induced significant increase in c-Src Y416 phosphorylation in GMCs but not in the total amount of c-Src (Figure 2C).

\section{Cx43 and c-Src are responsible for NF-kB activation induced by high glucose in GMCs}

Cx43 is known to be regulated by NF-kB $[20,21]$. Therefore, we sought to determine whether NF- $\mathrm{kB}$ is regulated by $\mathrm{Cx} 43$ in GMCs exposed to high glucose. We transfected GMCs with plasmids expressing Cx43-siRNA and GFPCx43, and analyzed Cx43 expression by immunoblotting. Our results showed that $\mathrm{Cx} 43$ expression was decreased by about $70 \%$ after Cx43-siRNA transfection, but increased by about $80 \%$ after GFP-Cx43 transfection. The empty vector had no effect on Cx43 expression. Immunofluorescence images of GFP-Cx43-transfected cells are shown in Figure 3B (a). Interestingly, nuclear translocation of NF- $\mathrm{BB}$ p65 by high glucose and $\mathrm{Cx} 43$-silencing was maintained in normal glucose. Furthermore, overexpression of $\mathrm{Cx} 43$ using GFP-Cx43 plasmid decreased NF- $\mathrm{kB}$ p65 activity in the nuclei of GMCs cultured in high glucose $(P<0.05$; Figure 3A). Immunofluorescence images also showed that high glucose and Cx43-siRNA transfection enhanced NF$\kappa B$ p65 nuclear translocation while GFP-Cx43-transfection 


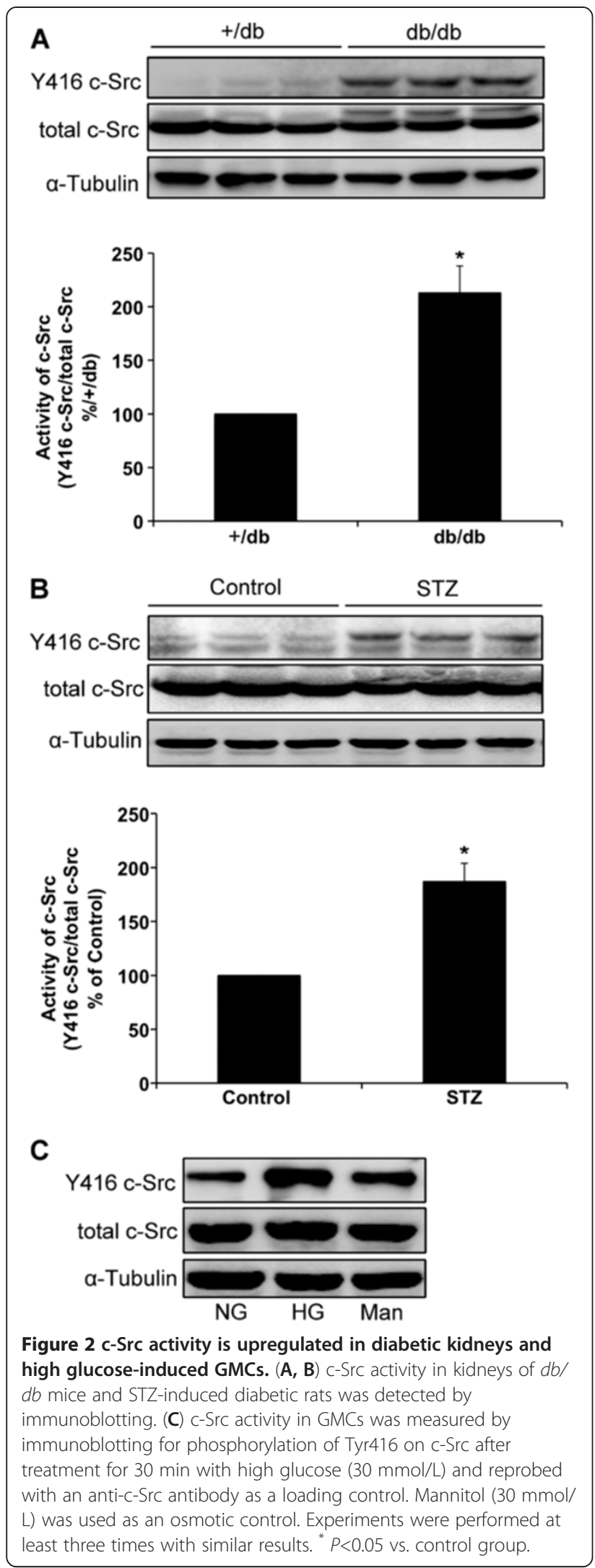

inhibited high glucose-induced NF-kB p65 nuclear translocation (Figure 3B (b)).

$\mathrm{c}-\mathrm{Src}$ is reportedly involved in NF-kB activation [22,23]. In a previous study, we showed that high glucose induces nucleus translocation NF-kB p65 [24]. In the current study, we found that preincubation with PP2 $(10 \mu \mathrm{M})$, an inhibitor of c-Src, prevented the increase in NF- $\mathrm{kB}$ p65 in the nuclei induced by high glucose $(P<0.05$; Figure $4 \mathrm{~A})$. Furthermore, PP2 also prevented nuclear translocation of NF- $\mathrm{kB}$ induced by $\mathrm{C} \times 43$ siRNA, suggesting the important role of $\mathrm{c}-\mathrm{Src}$ in NF- $\mathrm{kB}$ activation induced by $\mathrm{Cx} 43$ $(P<0.05$; Figure $4 \mathrm{~B}) . \mathrm{PP} 2$ also inhibited the upregulation of ICAM-1, TGF- $\beta 1$, and FN expression induced by high glucose in GMCs $(P<0.05$; Figure $4 \mathrm{C})$. An inactive analogue PP3 was used as a control and showed no effect.

\section{High glucose induces dissociation between $\mathrm{Cx} 43$ and} c-Src and enhances interaction between c-Src and IKB- $a$ in GMCs

Given the observations above, we further investigated the molecular mechanisms by which $\mathrm{Cx} 43$ mediates NF$\mathrm{kB}$ signalling in GMCs exposed to high glucose. The relationships among $\mathrm{Cx} 43, \mathrm{c}-\mathrm{Src}$ and IкB- $\alpha$ were investigated by co-immunoprecipitation and immunoblotting. Co-immunoprecipitation results revealed that high glucose decreased $\mathrm{Cx} 43$ and induced dissociation between $\mathrm{C} \times 43$ and c-Src $(P<0.05$; Figure $5 \mathrm{~A})$. Y416 c-Src expression was also increased without changes in the total amount of $\mathrm{c}-\mathrm{Src}$ by high glucose $(P<0.05$; Figure $5 \mathrm{~B})$. Furthermore, direct interaction between $c-S r c$ and IкB- $\alpha$ and tyrosine phosphorylation of IкB- $\alpha$ were observed $(P<0.05$; Figure $5 C)$. All of these changes were observed at $15 \mathrm{~min}$ of high glucose treatment and persisted for at least $120 \mathrm{~min}$. Serine phosphorylation of IкB- $\alpha$ and degradation of IкB- $\alpha$ were also observed by immunoblotting at $90 \mathrm{~min}$ of high glucose treatment, later than the emergence of NF-kB p65 nuclear translocation $(P<0.05$; Figure 5D).

Immunofluorescence images show the locations of $\mathrm{Cx} 43$, c-Src, and ІкB- $\boldsymbol{a}$ in GMCs

We next performed immuofluorescence staining of Cx43, c-Src, and IkB- $\alpha$ in GMCs to confirm our coimmunoprecipitation results. Zonula occludens-1 (ZO-1), originally identified as a component of tight junctions, is a member of the membrane-associated guanylate kinase family of proteins that interacts with $\mathrm{Cx} 43$ at the plasma membrane [25]. Cx43 and ZO-1 were found to co-localize at the membrane of GMCs cultured in normal glucose. However, a significant decrease in the membrane Cx43 of GMCs was observed after $30 \mathrm{~min}$ of high glucose treatment (Figure 6A (a)). c-Src was also found to be located on the membrane of GMCs cultured in normal glucose. High glucose induced its translocation to the cytoplasm 


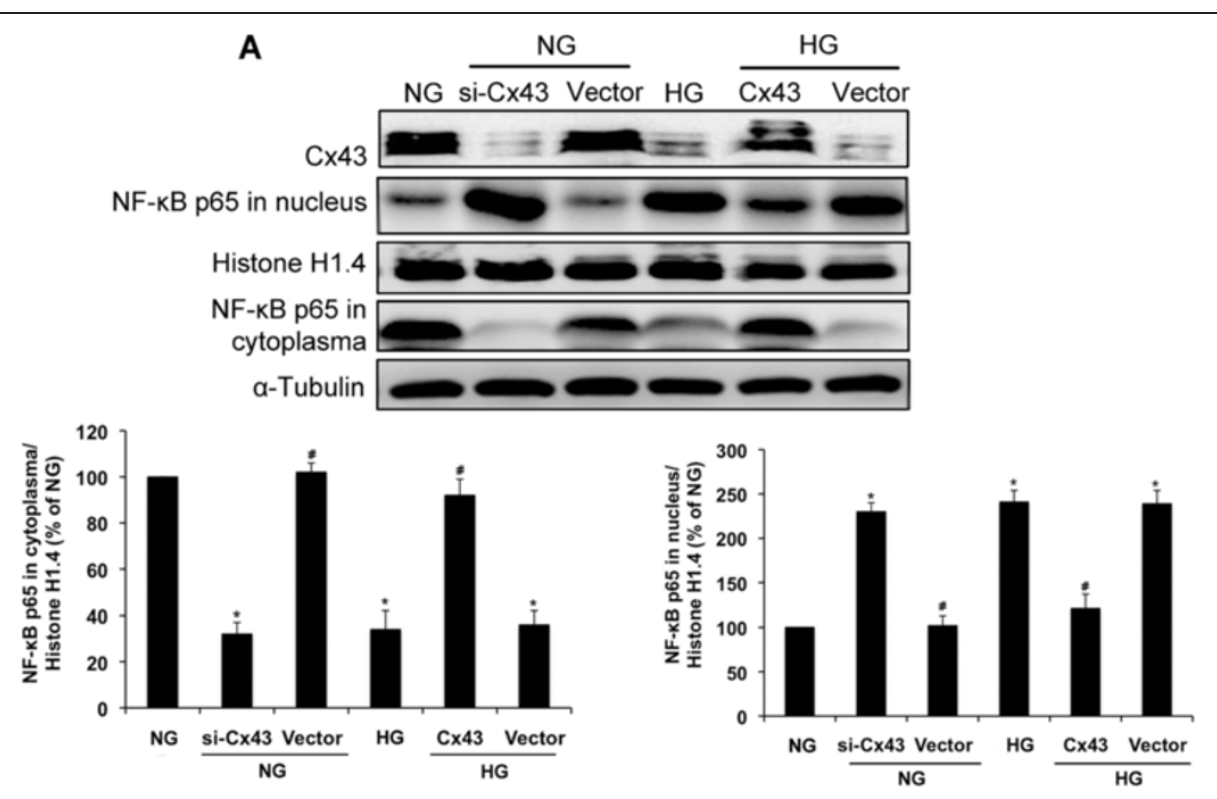

B

a

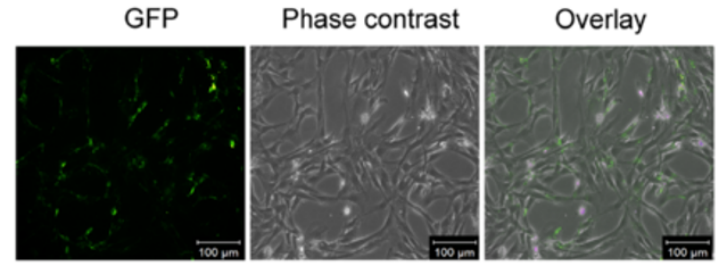

b

Cx43

NF-KB p65

Nuclei

Overlay
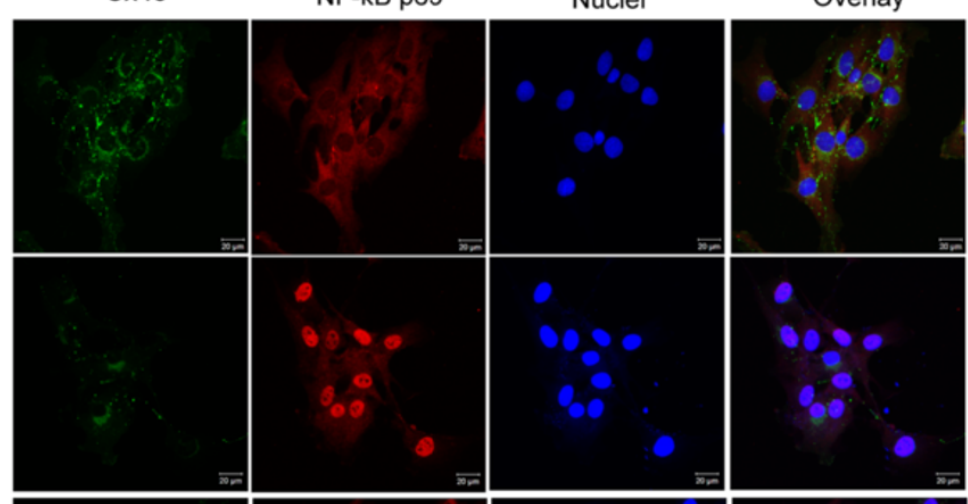

NG+

Cx43-siRNA
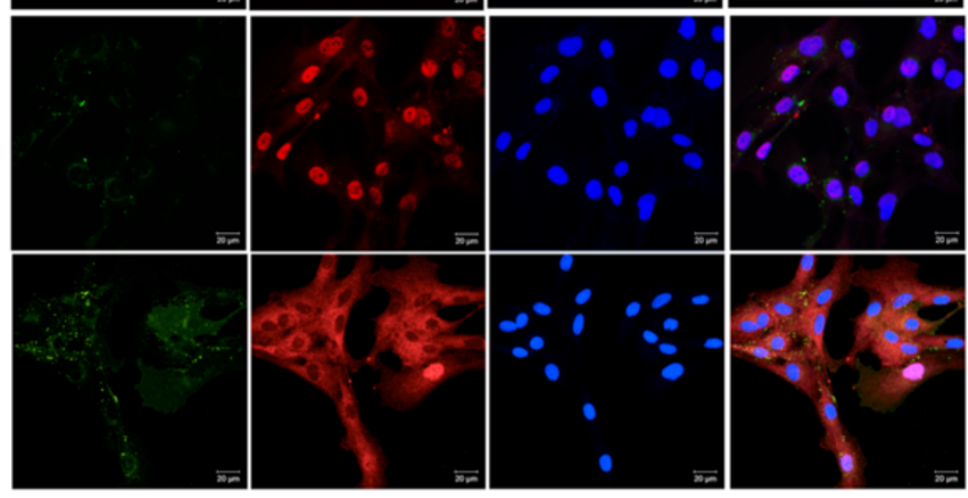

Figure 3 (See legend on next page.) 
(See figure on previous page.)

Figure 3 Cx43 regulates high glucose-induced NF-кB nuclear translocation. (A) GMCs were transfected with Cx43-siRNA or GFP-Cx43 in normal glucose (NG; $5.5 \mathrm{mmol} / \mathrm{L}$ ). After $48 \mathrm{~h}$ of transfection, GMCs were exposed to high glucose (HG; $30 \mathrm{mmol} / \mathrm{L})$ for 30 min. Proteins were then extracted for analysis of Cx43 expression and NF-KB p65 nuclear translocation by immunoblotting. (B) Immunofluorescence images of GFP were captured under a laser scanning confocal microscope to assess the transfection efficiency of GFP-Cx43. Green fluorescence indicates GFP. Scale bar represents $100 \mu \mathrm{m}$ (magnification 100X, a). Immunofluorescence images stained doubly with anti-Cx43 antibody and anti-NF-KB p65 antibody were captured under a laser scanning confocal microscope (magnification 400x, b). High glucose and Cx43-siRNA-transfection enhance NF-KB p65 nuclear translocation and GFP-Cx43-transfection inhibits high glucose-induced NF-KB p65 nuclear translocation. Red fluorescence indicates localization of NF-KB p65. Green fluorescence indicates localization of Cx43. Blue fluorescence indicates nuclei. Scale bar represents $20 \mu \mathrm{m}$. Experiments were performed at least three times with similar results. ${ }^{*} P<0.05 \mathrm{vs}$. normal glucose-treated group, ${ }^{\#} P<0.05 \mathrm{vs} .30 \mathrm{mmol} / \mathrm{L}$ glucose-treated group.

(Figure 6A (b)). Furthermore, an abundance of $\mathrm{Cx} 43$ and the majority of c-Src were found to localize on the membrane of GMCs maintained in normal glucose (Figure 6B (a)). No co-localization was observed between c-Src and IкB- $\alpha$ (Figure 6B (b)). However, Cx43 expression on the membrane decreased after high glucose treatment (Figure 6B (a).) Meanwhile, c-Src was translocated to the cytoplasm of GMCs, where it interacted with IkB- $\alpha$ (Figure 6B (b)).

\section{Cx43 and c-Src regulate tyrosine phosphorylation of ІкB- $\mathrm{a}$ induced by high glucose in GMCs}

To determine whether regulation of NF- $\mathrm{kB}$ by $\mathrm{Cx} 43$ and c-Src involves tyrosine phosphorylation of IкB- $\alpha$, plasmids of Cx43-siRNA and GFP-Cx43, and PP2, a c-Src inhibitor, were used. High glucose alone and transfection of Cx43-siRNA induced tyrosine phosphorylation of IкB- $\alpha$ and interaction between c-Src and IкB- $\alpha$ in GMCs cultured in normal glucose. However, pretreatment with PP2 $(10 \mu \mathrm{M})$ significantly inhibited tyrosine phosphorylation of IкB- $\alpha$ induced by high glucose $(P<0.05$; Figure $7 \mathrm{~A})$. Restoration of $\mathrm{Cx} 43$ by transfection of GFP-Cx43 decreased tyrosine phosphorylation of IкB- $\alpha$ and interaction between $\mathrm{c}-\mathrm{Src}$ and IкB- $\alpha$ induced by high glucose $(P<0.05$; Figure 7B).

\section{Cx43CT plays an important role in the regulation of NF-KB by $\mathrm{Cx} 43$ independent of GJIC}

Flag-Cx43CT, which consists of the intracellular carboxy tail of $\mathrm{Cx} 43$ tagged with FLAG, was used to determine whether regulation of NF- $\mathrm{kB}$ by $\mathrm{Cx} 43$ is independent of GIIC. Results of scrape-loading experiments showed that GJIC inhibited by high glucose was restored by transfection of GFP-Cx43. Flag-Cx43CT did not show any effect (Figure 8A). Like GFP-Cx43, transfection with Flag$\mathrm{Cx} 43 \mathrm{CT}$ also significantly inhibited high glucose-induced NF-кB p 65 nuclear translocation $(P<0.05$; Figures $8 B)$. Additionally, transfection with Flag-Cx43CT exhibited an inhibitory effect on c-Src activation induced by high glucose in GMCs. Our observation of co-immunoprecipitation between $\mathrm{c}-\mathrm{Src}$ and FLAG suggests a direct interaction between Flag-Cx43CT and c-Src $(P<0.05$; Figures $8 C)$.
Cx43 inhibits upregulation of ICAM-1, TGF- $\beta 1$, and FN expression induced by high glucose in GMCs

ICAM- 1 and TGF- $\beta 1$ are well-known important inflammatory factors in the pathogenesis of DN [26-30]. FN is an important ECM component in the kidney $[1,2]$. Treatment with high glucose for $24 \mathrm{~h}$ markedly increased ICAM-1, TGF- $\beta 1$, and FN protein levels compared with the control group $(P<0.05$; Figure $9 \mathrm{~A})$. However, GFP$\mathrm{Cx} 43$ or Flag-Cx43CT-transfection in high glucose-treated GMCs significantly inhibited upregulation of these proteins. Transfection with the vector alone had no effect on the production of ICAM- 1 , TGF- $\beta 1$, and FN proteins $(P<0.05$; Figure 9A). Cx43-siRNA had similar effects as high glucose for FN, ICAM-1 and TGF- $\beta 1$. Restoration of Cx43 by transfection of GFP-Cx43 attenuated FN, ICAM1 and TGF- $\beta 1$ accumulation $(P<0.05$; Figure $9 \mathrm{~B})$. Immunofluorescence staining also revealed that FN was upregulated by high glucose or Cx43-siRNA, and restoration of $\mathrm{Cx} 43$ by GPF-Cx43-transfection attenuated FN upregulation induced by high glucose (Figure $9 \mathrm{C}$ ).

\section{Discussion}

Downregulation of Cx43 protein expression has been observed in the kidneys of diabetic animals and high glucose-treated GMCs [11-14]. Consistent with previous studies, we observed that the protein level of $\mathrm{Cx} 43$ was reduced in the kidneys of $d b / d b$ mice and STZ-induced diabetic rats. Furthermore, significantly reduced Cx43 protein level was observed after $30 \mathrm{~min}$ of high glucose exposure in GMCs. Previous studies have reported that the half-life of $\mathrm{Cx} 43$ is short- as litter as 1-2 hours [31-33]. We explored the half-life of Cx43 in GMCs cultured in normal glucose or high glucose using cycloheximide. A significant decrease in Cx43 was observed after $30 \mathrm{~min}$ of normal glucose $(5.5 \mathrm{mM})$ exposure. However, high glucose $(30 \mathrm{mM})$ induced a faster decrease in $\mathrm{Cx} 43$ after 15 min stimulation, suggesting Cx43 is actively degraded (Additional file 1: Figure S1). In our previous study, we found that NF- $\mathrm{kB}$ signalling is activated in the kidneys of diabetic rats and high glucose-treated GMCs [24]. While several studies have investigated the relationship between $\mathrm{Cx} 43$ and NF- $\mathrm{kB}$ signalling, most of them have focused only on the regulation of $\mathrm{Cx} 43$ by NF-kB. 


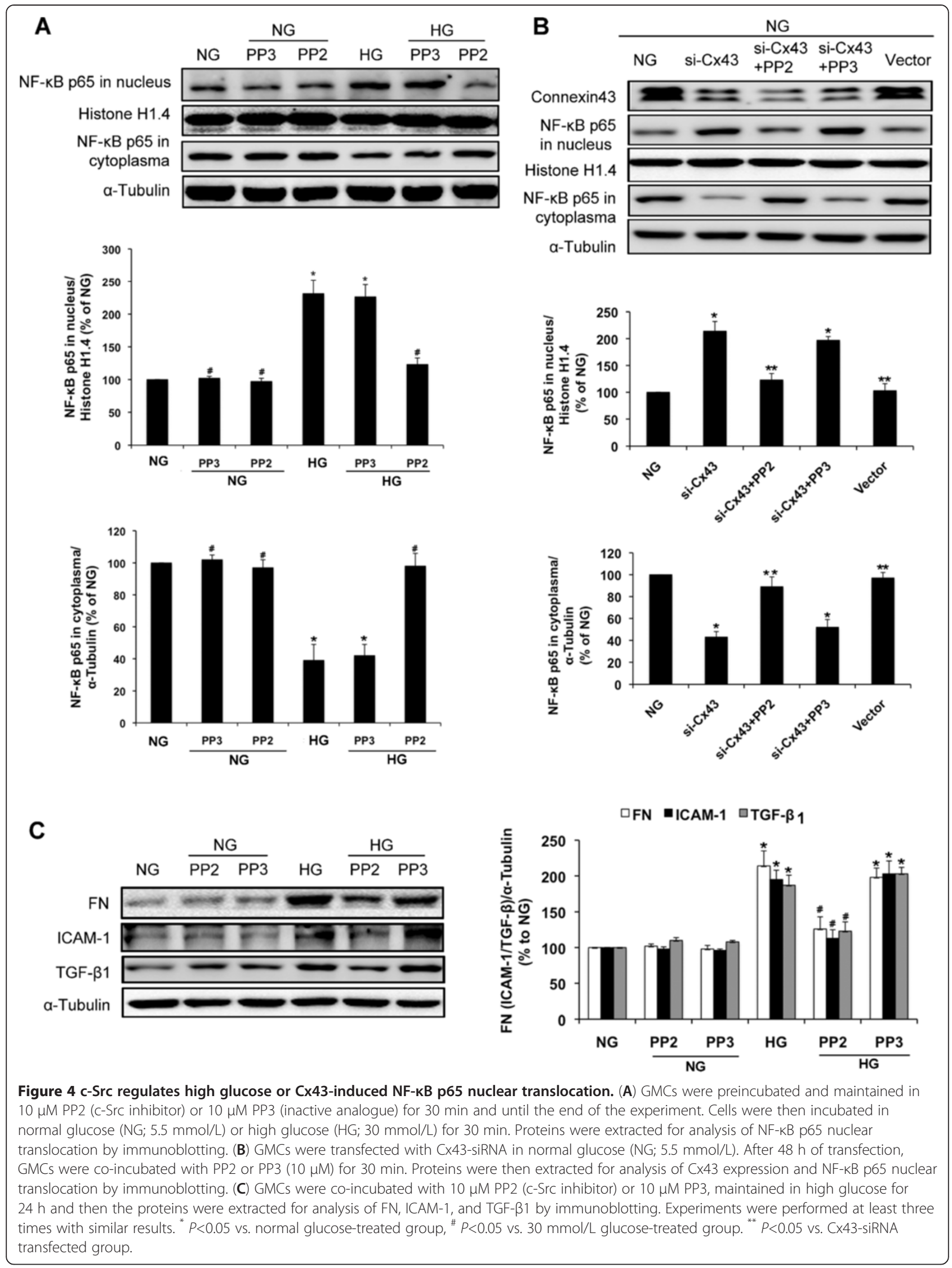




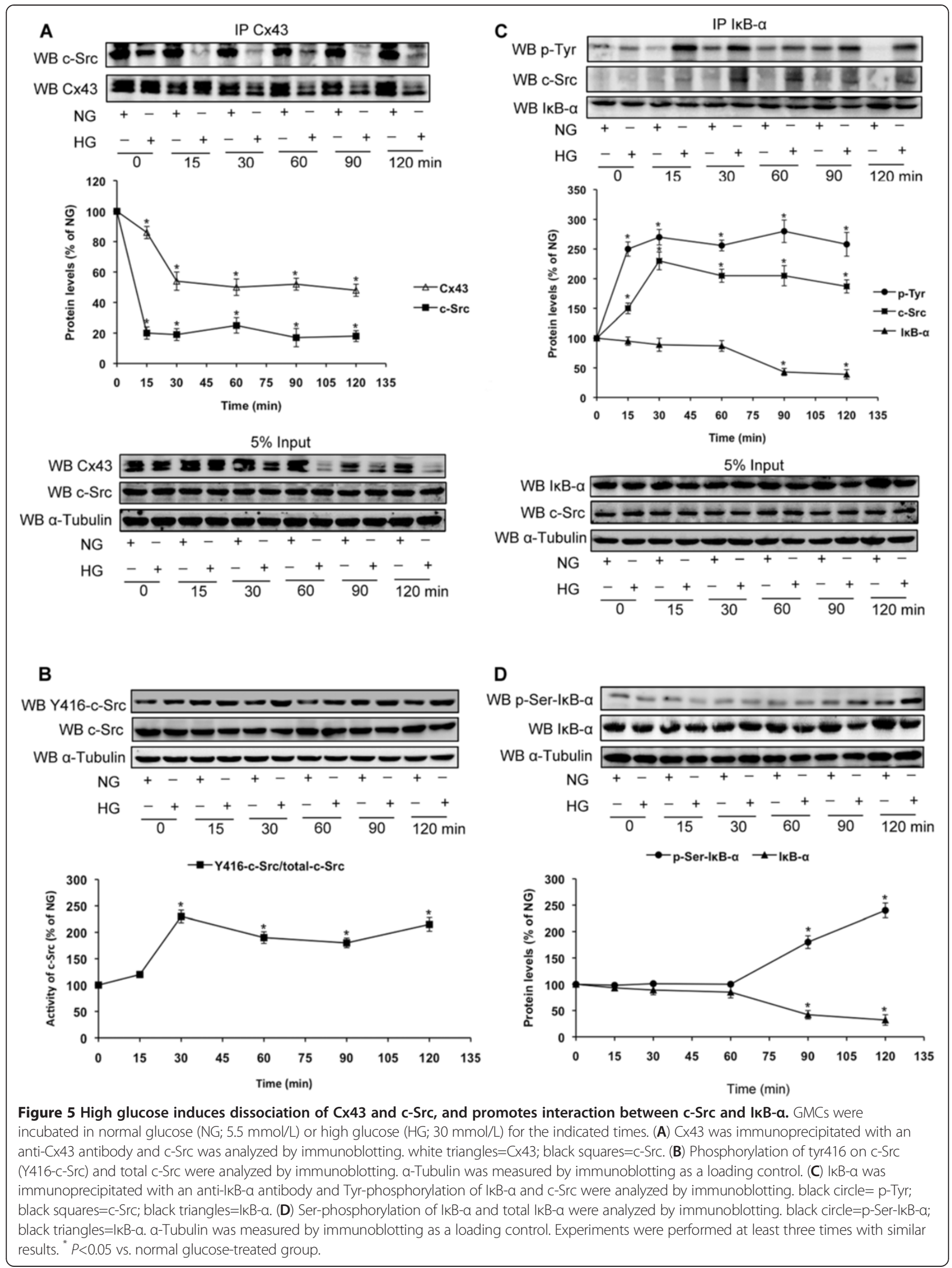



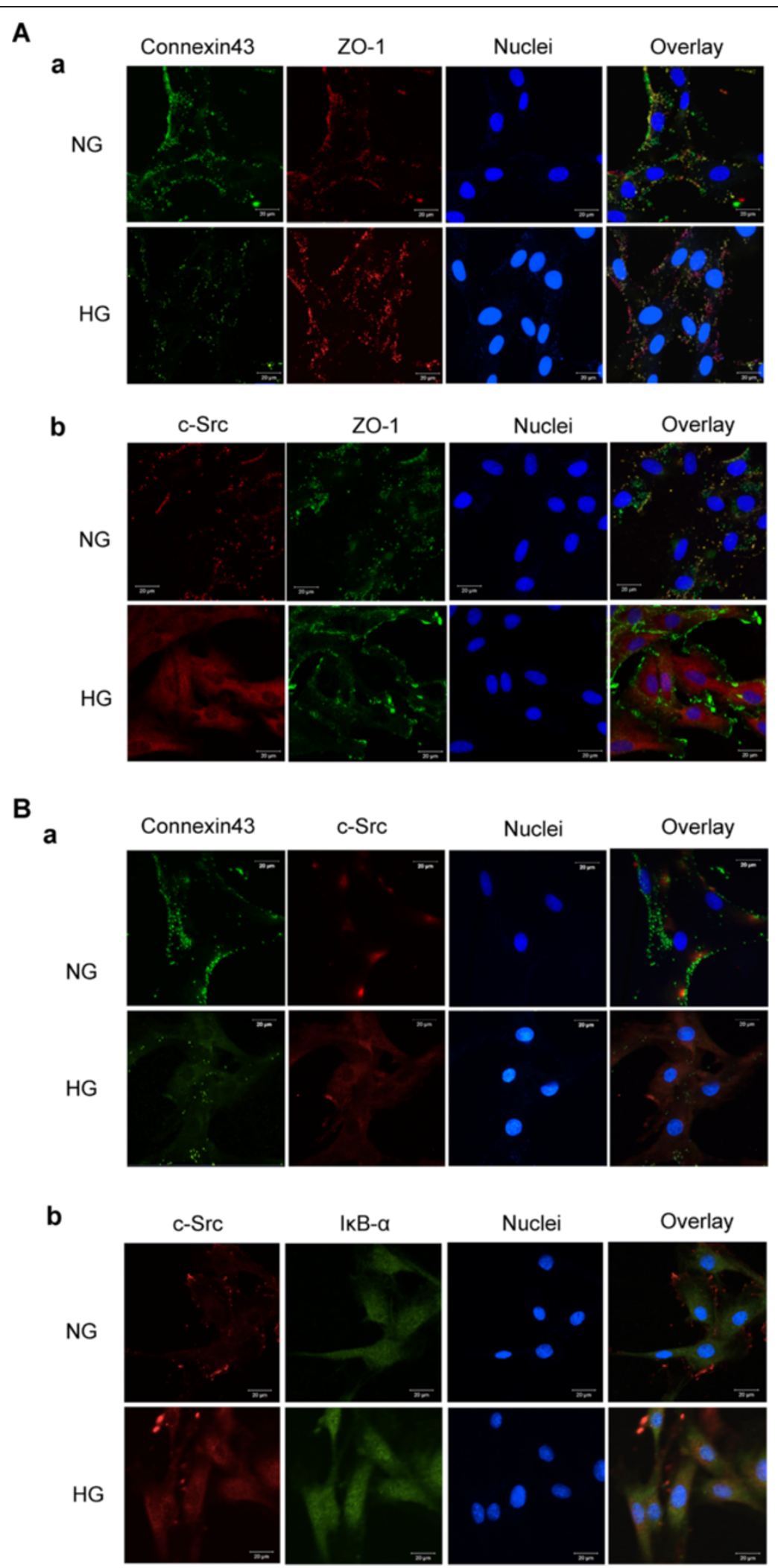

Figure 6 (See legend on next page.) 
(See figure on previous page.)

Figure 6 Immunofluorescence images of co-localization of Cx43, c-Src and IkB- $\boldsymbol{a}$ in GMCs. GMCs were incubated in normal glucose (NG; $5.5 \mathrm{mmol} / \mathrm{L}$ ) or high glucose (HG; $30 \mathrm{mmol} / \mathrm{L}$ ) for $30 \mathrm{~min}$. (A (a)) Confocal microscopy was used to evaluate the localization of $\mathrm{Cx} 43$ under normal glucose or high glucose conditions. Green fluorescence indicates localization of Cx43. Red fluorescence indicates ZO-1, which served as a cytomembrane marker. Blue fluorescence indicates nuclei. (A (b)) Confocal microscopy was used to evaluate the localization of c-Src under normal glucose or high glucose conditions. Red fluorescence indicates c-Src. Green fluorescence indicates localization of ZO-1. Blue fluorescence indicates nuclei. (B (a)) Confocal microscopy was used to evaluate the localization of Cx43 and c-Src under normal glucose or high glucose conditions. A significant decrease in Cx43 was observed after high glucose treatment. c-Src dissociated from Cx43 and translocated into the cytoplasm after high glucose treatment. Green fluorescence indicates localization of Cx43. Red fluorescence indicates c-Src localization. Blue fluorescence indicates nuclei. (B (b)) Confocal microscopy was used to evaluate the localization of c-Src and IkB-a. c-Src was translocated into the cytoplasm from the cytomembrane after high glucose treatment and then co-localized with IKB- $a$ in the cytoplasm of GMCs. Green fluorescence indicates localization of IKB-a. Red fluorescence indicates c-Src localization. Blue fluorescence indicates nuclei. Scale bar represents $20 \mu \mathrm{m}$ (magnification 630x).

For instance, AngII has been found to induce binding of $\mathrm{NF}-\mathrm{k} B$ to the $\mathrm{Cx} 43$ gene promoter, increasing $\mathrm{Cx} 43$ expression in aortic smooth muscle cells while the TLR3 ligand polyl:C has been observed to induce downregulation of Cx43 by a mechanism involving NF-kB [20,21].

In the present study, we found that downregulation of Cx43 induced by high glucose or transfection with the Cx43-siRNA plasmid enhanced nuclear translocation of NF-kB p65. However, restoration of Cx43 expression by transfection with GFP-Cx43 attenuated high glucoseinduced NF- $\mathrm{kB}$ p65 nuclear translocation in GMCs, which suggests that decreased $\mathrm{Cx} 43$ expression mediates NF- $\mathrm{kB}$ activation in GMCs. Thus, our findings show that Cx43 participates in the activation of NF-kB in high glucose-treated GMCs and enhances the relationship between NF- $k B$ and Cx43. The molecular mechanism of this cellular event, however, remains unclear.

We also observed upregulation of c-Src activity in the kidneys of $d b / d b$ mice and STZ-induced diabetic rats. Previous studies have shown that high glucose can activate cSrc $[34,35]$. Consistent with such findings, our results show that c-Src is activated in high glucose-treated GMCs. c-Src has been proposed to be responsible for the pathogenesis of DN. We used PP2, a c-Src inhibitor, to explore whether c-Src is involved in the high glucose-induced activation of NF- $\mathrm{kB}$ signalling in GMCs. We found that PP2 inhibited NF-кB p65 nuclear translocation induced by high glucose or $\mathrm{Cx} 43$ silencing, suggesting the important role of $\mathrm{c}$-Src in Cx43-induced NF- $\mathrm{kB}$ activation.

As mentioned above, both $\mathrm{Cx} 43$ and c-Src are involved in the activation of NF- $\mathrm{kB}$ in high glucose-treated GMCs. Therefore, we further explored the molecular mechanisms involved in these events. Previous studies have indicated that phosphorylation of $\mathrm{Cx} 43$ by c-Src reduces gap junctional communication depending on the interaction between $\mathrm{Cx} 43 \mathrm{CT}$ and c-Src $[17,36]$. Interestingly, recent studies have suggested that the interaction between $\mathrm{Cx} 43$ and c-Src reciprocally modulates their activities. The level of $\mathrm{C} 433$ expression is important in regulating c-Src activity. Upregulation of Cx43 in glioma cells reduces c-Src activity while silencing of $\mathrm{Cx} 43$ activates c-Src in astrocytes
[37,38]. In our study, reduction of $\mathrm{Cx} 43$ protein level induced by high glucose was accompanied by decrease in the amount of c-Src interacting with $\mathrm{Cx} 43$, thereby increasing the activity of c-Src in the cytoplasm. This finding indicates that downregulation of $\mathrm{Cx} 43$ by high glucose activates c-Src.

The molecular mechanism by which c-Src regulates $N F-\kappa B$ has been suggested to be dependent on the interaction between c-Src and IкB kinase $\beta$ (IKK $\beta$ ) or IкB$\alpha$. IKK $\beta$ is phosphorylated by $\mathrm{c}-\mathrm{Src}$, which is involved in TNF- $\alpha$-induced ICAM-1 expression [22]. Tyrosine phosphorylation of IKB- $\alpha$ activates NF- $\mathrm{KB}$ through a redox-regulated and c-Src-dependent mechanism following hypoxia/reoxygenation [23]. In the current study, IкB- $\alpha$ was found to interact with c-Src after exposure of GMCs to high glucose for $15 \mathrm{~min}$, and to be accompanied by tyrosine phosphorylation of ІкВ- $\alpha$, persisting for at least $120 \mathrm{~min}$. We have previously shown that NF-KB p65 is translocated into the nucleus after exposure of GMCs to high glucose levels for $30 \mathrm{~min}$ [24]. Interestingly, IKK-mediated serine phosphorylation of IKB- $\alpha$, a classic pathway of NF-kB activation [39], was detected after exposure of GMCs to high glucose levels for 90 $\mathrm{min}$, and this was accompanied by degradation of IкB- $\alpha$, which occurs after NF- $\mathrm{kB}$ p65 nuclear translocation. Thus, tyrosine phosphorylation of ІкB- $\alpha$ could possibly play an important role in the initial step of high glucoseinduced NF- $\mathrm{kB}$ p65 activation. As described in a previous study, tyrosine phosphorylation activates NF- $\mathrm{kB}$ without degradation of IкB- $\alpha$ [40]. We did not observe degradation of I $\mathrm{kB}-\alpha$ when NF- $\kappa \mathrm{B}$ p65 was translocated into the nucleus at early stages of exposure of GMCs to high glucose.

Immunofluorescence images showed that $\mathrm{Cx} 43$ and c-Src were co-localized around the cell membrane in GMCs maintained in normal glucose. There was no interaction between c-Src and IKB- $\alpha$ in GMCs cultured in normal glucose. However, co-localization of c-Src and IкB- $\alpha$ was observed in the cytoplasm after exposure of GMCs to high glucose for $30 \mathrm{~min}$. Based on these data, we propose that decrease in $\mathrm{Cx} 43$ expression enhances 


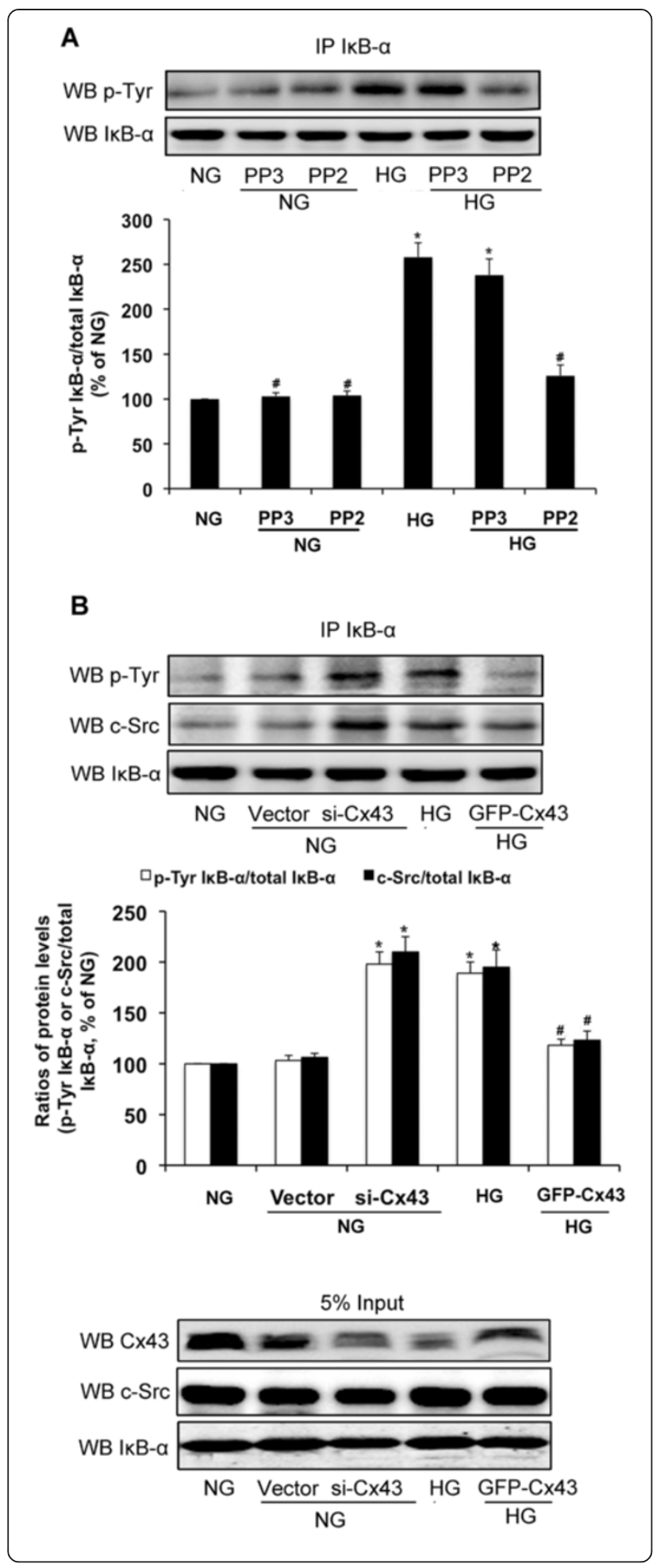

Figure 7 Cx43 and c-Src are responsible for high glucoseinduced Tyr-phosphorylation of ІкB-a. (A) GMCS were preincubated and maintained in $10 \mu \mathrm{M}$ PP2 (c-Src inhibitor) or 10 HM PP3 (inactive analogue of PP2) for $30 \mathrm{~min}$ and until the end of the experiment. Cells were then incubated in normal glucose (NG; $5.5 \mathrm{mmol} / \mathrm{L}$ ) or high glucose ( $\mathrm{HG} ; 30 \mathrm{mmol} / \mathrm{L}$ ) for $30 \mathrm{~min}$ and $\mathrm{lkB}-\mathrm{a}$ was immunoprecipitated with an anti-1kB- $a$ antibody. Tyrphosphorylation of IKB- $a$ and total-IKB-a were then analyzed by immunoblotting. (B) GMCs were transfected with Cx43-siRNA or GFP-CX43 under the condition of normal glucose (NG; $5.5 \mathrm{mmol} / \mathrm{L}$ ). After $48 \mathrm{~h}$ of transfection, GMCs were exposed to high glucose (HG; $30 \mathrm{mmol} / \mathrm{L}$ ) for $30 \mathrm{~min}$. IKB-a was immunoprecipitated with an antiIKB-a antibody, and Tyr-phosphorylation of IKB- $\mathrm{K}$ and $c-S r c$, and total-IKB-a were analyzed by immunoblotting. Experiments were performed at least three times with similar results. ${ }^{*} P<0.05$ vs. normal glucose-treated group, ${ }^{\#} P<0.05$ vs. $30 \mathrm{mmol} / \mathrm{L}$ glucose-treated group.

the activity of c-Src by acting as a substrate of the kinase, which promotes interaction between $\mathrm{c}$-Src and IKB$\alpha$ and leads to NF- $k B$ activation. The results of our study confirm that PP2, an inhibitor of c-Src, can inhibit the tyrosine phosphorylation of IкB- $\alpha$ and translocation of NF-kB p65 into the nucleus, which suggests that c-Src regulates NF- $\kappa B$ by inducing tyrosine phosphorylation of I $\mathrm{B}-\alpha$.

A recent study has reported that silencing $\mathrm{Cx} 43$ activates $\mathrm{c}-\mathrm{Src}$, which in turn upregulates HIF-1 $\alpha$ leading to the upregualtion of the machinery required to take up glucose in astrocytes [38]. Thus, c-Src is an important factor in the regulation of nuclear transcription factors by $\mathrm{Cx} 43$. In this study, we found that high glucose and silencing of $\mathrm{Cx} 43$ induced c-Src activation and promoted interaction between $\mathrm{c}-\mathrm{Src}$ and IKB- $\alpha$ in GMCs cultured in normal glucose. Restoration of Cx43 greatly attenuated these changes in GMCs cultured in high glucose, confirming that the interaction between $\mathrm{c}$-Src and IkB- $\alpha$ is regulated by $\mathrm{Cx} 43$. We also explored the relationship of HIF- $1 \alpha$ and Cx43 in GMCs. HIF- $1 \alpha$ protein level was upregulated by high glucose or reduced $\mathrm{Cx} 43$ level in GMCs. Inhibition of c-Src or NF- $\mathrm{kB}$ abrogated the increase in HIF- $1 \alpha$ protein level induced by high glucose. The increase in HIF- $1 \alpha$ protein level was associated with significant accumulation of FN, ICAM- 1 and TFG- $\beta 1$ in GMCs exposed to high glucose, suggesting a potential role of HIF- $1 \alpha$ in the pathogenesis of DN. However, further research is needed to define the role of HIF-1 $\alpha$ in DN (Additional file 2: Figure S2).

The regulation of NF- $\mathrm{kB}$ by reduced $\mathrm{Cx} 43$ protein level could be caused by absence of $\mathrm{Cx} 43$ function (gap junctional communication) or absence of $\mathrm{Cx} 43$ interactions with other proteins, such as c-Src. Restoration of Cx43CT, a non-channel forming region, increases the expression of the intracellular carboxy tail of $\mathrm{Cx} 43$ without affecting GJIC [37]. Consistent with previous observations, our results showed that restoration of $\mathrm{Cx} 43$ 

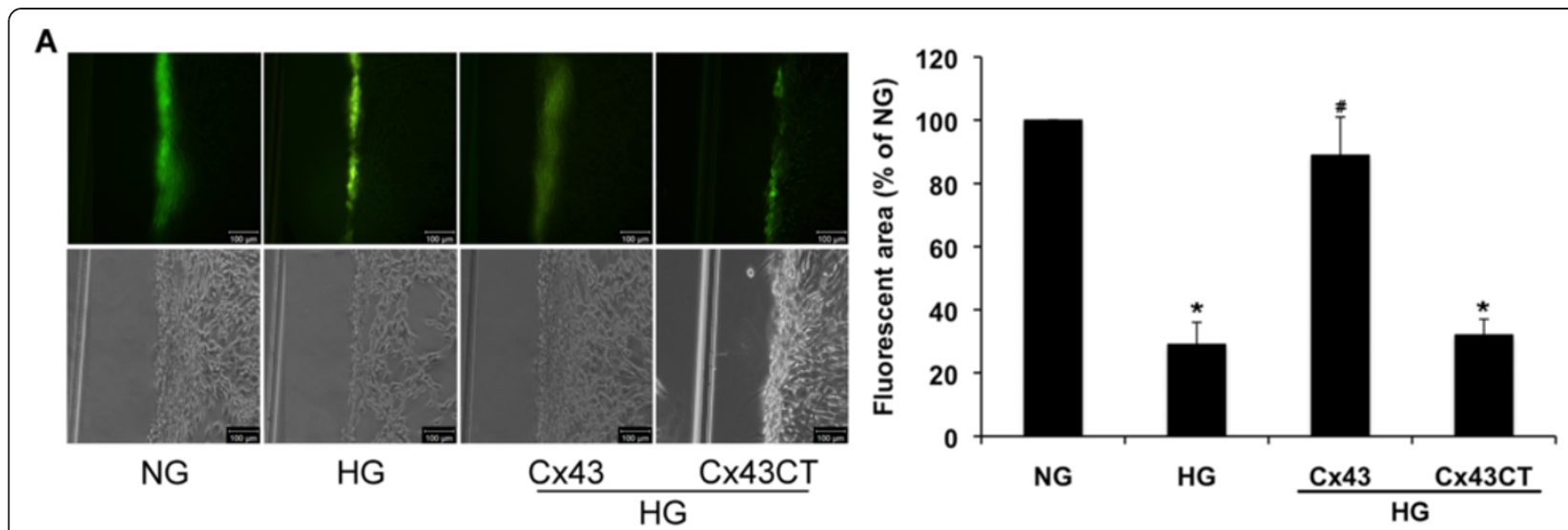

B

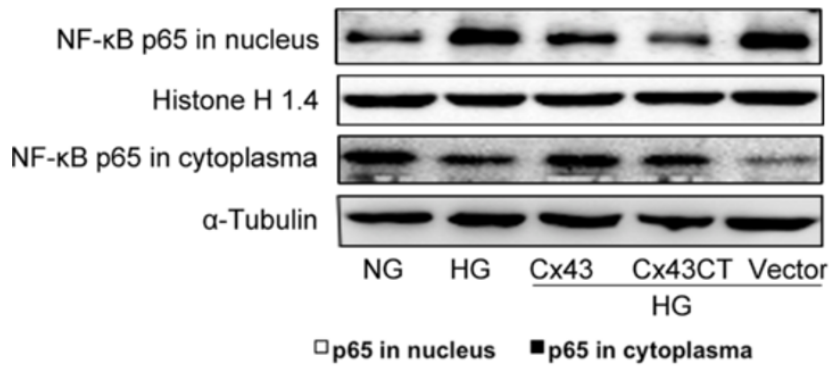

C

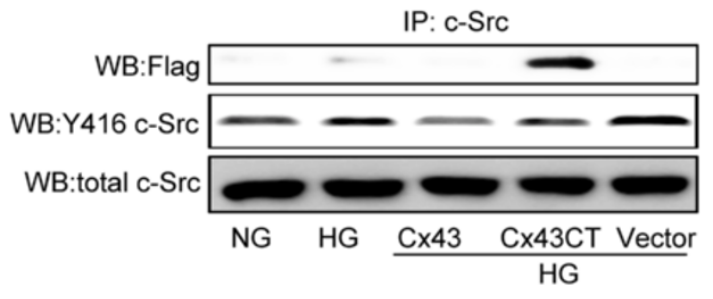

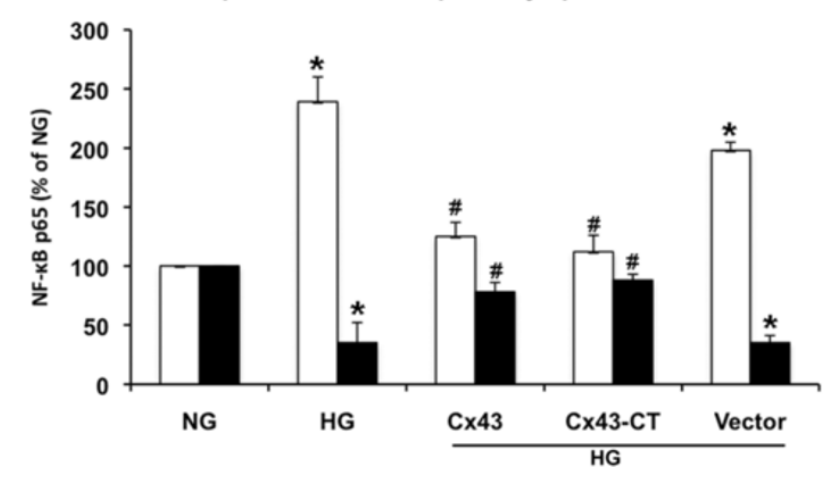

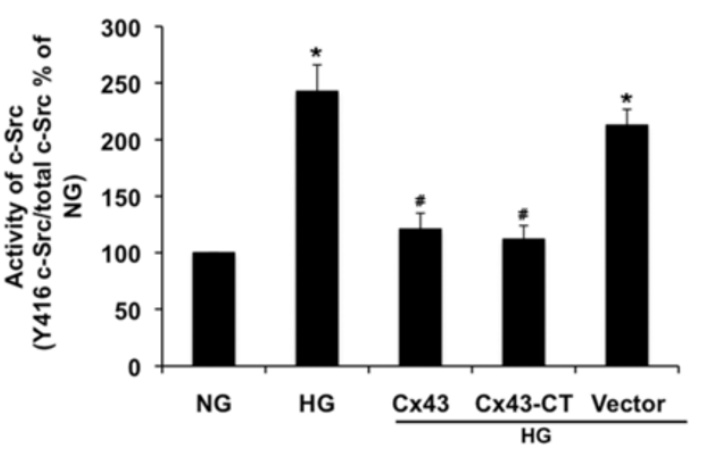

Figure 8 Regulation of high glucose-induced NF-KB nuclear translocation and c-Src activity by Cx43 is independent of GJIC. GMCs were transfected with GFP-Cx43 or Flag-Cx43CT under the condition of normal glucose (NG; 5.5 mmol/L). After 48 h of transfection, GMCs were exposed to high glucose (HG; 30mmol/L) for $30 \mathrm{~min}$. (A) Photomicrographs obtained after Lucifer yellow scrape-loading in GMCs transfected with GFP-CX43 and Flag-Cx43CT (magnification 100x, upper panel). Phase contrast views are also provided (lower panel). Scale bar represents $100 \mu \mathrm{m}$. (B) Proteins were extracted for analysis of NF-KB p65 nuclear translocation by immunoblotting. Histone H1.4 and a-tubulin were measured by immunoblotting as a loading control. (C) c-Src was immunoprecipitated with an anti-c-Src antibody and Flag, phosphorylation of Tyr416 on c-Src (Y416-c-Src) and total c-Src were analyzed by immunoblotting. Experiments were performed at least three times with similar results. ${ }^{*} P<0.05$ vs. normal glucose-treated group, ${ }^{\#} P<0.05$ vs. $30 \mathrm{mmol} / \mathrm{L}$ glucose-treated group.

rebuilt GIC inhibited by high glucose. However, Cx43CT overexpression did not exhibit such effects. Similar to the restoration of $\mathrm{Cx} 43$, Cx43CT reduced the activation of c-Src and NF- $k B$ in GMCs exposed to high glucose, which suggests that this effect depends mostly on the interaction between $\mathrm{Cx} 43 \mathrm{CT}$ and c-Src.

Our results confirm our hypothesis that $\mathrm{Cx} 43$ regulates the activity of c-Src in high glucose-treated GMCs and activates NF-kB. We further investigated the effects of $\mathrm{C} x 43$ on protein expression of target genes of NF- $\mathrm{kB}$, including ICAM-1 and TGF- $\beta 1$, in high glucose-treated GMCs. ICAM-1 is an important downstream inflammatory factor whose gene contains an NF-kB binding site in the promoter region [41]. ICAM-1 gene deficiency prevents nephropathy in type 2 diabetic $\mathrm{db} / \mathrm{db}$ mice $[26,27]$. TGF- $\beta 1$ is recognised as another important factor in DN pathogenesis by mediating inflammatory responses, which aggravates accumulation of the ECM proteins FN and collagen, and interstitial myofibroblast activation, a critical event in the pathogenesis of interstitial fibrosis [28-30]. 
B
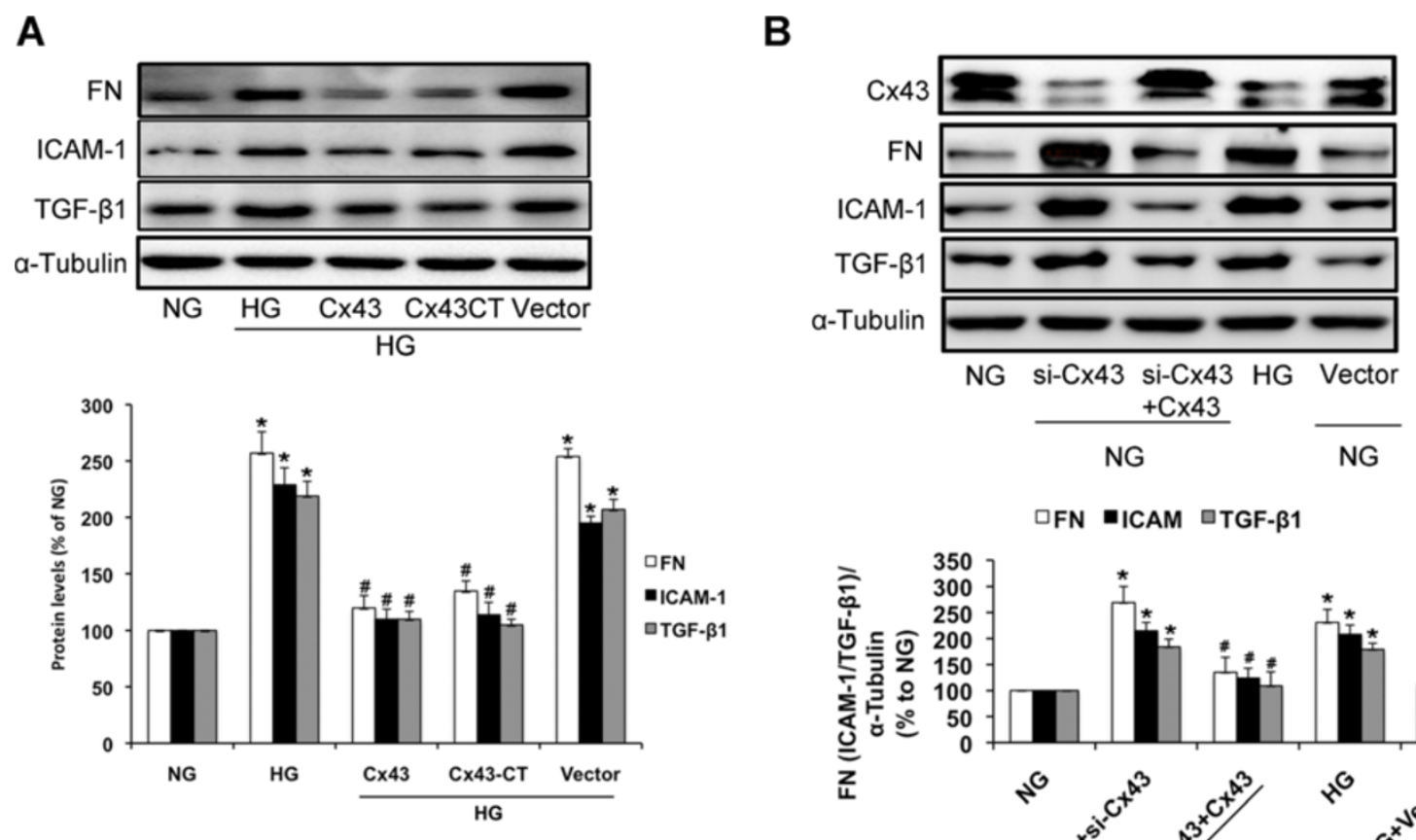

口FN =ICAM $\square T G F-\beta 1$

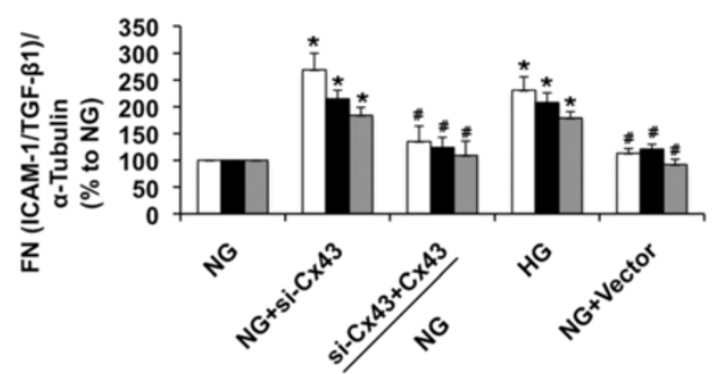

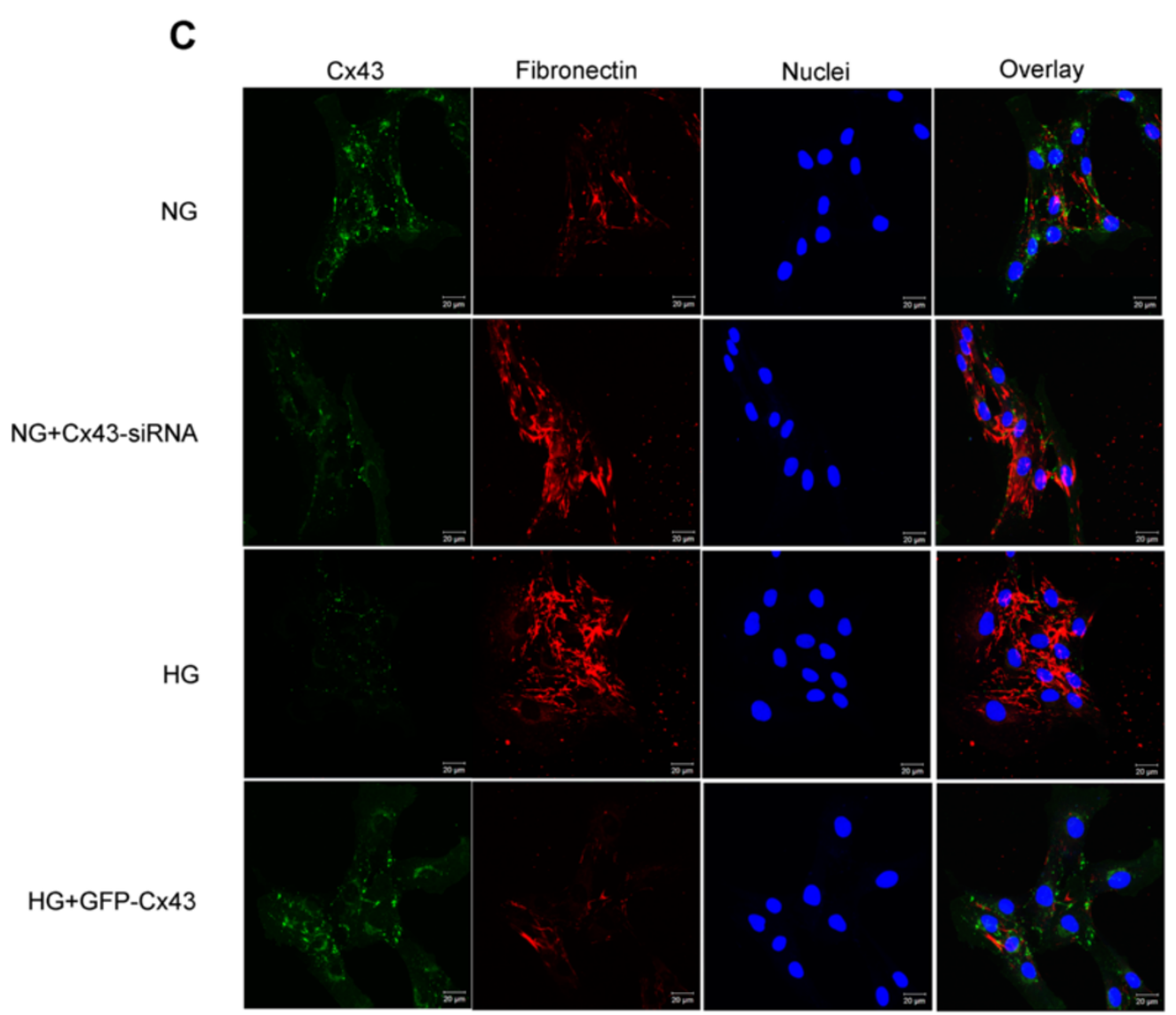

Figure 9 (See legend on next page.) 
(See figure on previous page.)

Figure 9 Cx43 inhibits high glucose-induced expression of FN, ICAM-1, and TGF- $\beta 1$. (A) GMCs were transfected with GFP-CX43 or FlagCx43CT in normal glucose (NG; $5.5 \mathrm{mmol} / \mathrm{L})$. After $48 \mathrm{~h}$ of transfection, GMCs were exposed to high glucose (HG; $30 \mathrm{mmol} / \mathrm{L})$ for $24 \mathrm{~h}$. Proteins were extracted for analysis of FN, ICAM-1, and TGF- $\beta 1$ by immunoblotting. (B) GMCs were transfected with Cx43-siRNA in normal glucose. After $24 \mathrm{~h}$, cells were then transfected with GFP-Cx43 to restore Cx43 expression. Proteins were extracted for analysis of FN, ICAM-1, and TGF- $\beta 1$ by immunoblotting. The high glucose-treated group was used as the control. (C) Immunofluorescence images stained doubly with anti-Cx43 antibody and anti-FN antibody were captured under a laser scanning confocal microscope (magnification 630x). Green fluorescence indicates Cx43. Red fluorescence indicates FN. Blue fluorescence indicates nuclei. Scale bar represents $20 \mu \mathrm{m}$. Experiments were performed at least three times with similar results. ${ }^{*} P<0.05$ vs. normal glucose-treated group, ${ }^{\#} P<0.05$ vs. $30 \mathrm{mmol} / \mathrm{L}$ glucose-treated group.

In the current study, restoration of $\mathrm{Cx} 43$ or $\mathrm{Cx} 43 \mathrm{CT}$ reversed high glucose-induced increases in ICAM-1 and TGF- $\beta 1$ protein expression in GMCs. FN is an important factor in the ECM and excessive synthesis of it contributes to glomerular basement membrane thickening and glomerular sclerosis. Several studies have proposed that $\mathrm{Cx} 43$ may play an important role in cardiac and pulmonary fibrosis. Mice lacking $\mathrm{Cx} 40$ and endothelial cell $\mathrm{Cx} 43$ have lung dysfunction and fibrosis [42]. Reduced Cx43 expression increases fibrosis and pro-arrhythmia in aged and pressure-overloaded mice due to enhanced fibroblast activity [43]. In our study, high glucose or silencing of Cx43 by Cx43-siRNA induced the upregulation of ICAM-1, TGF- $\beta 1$ and FN. Overexpression of Cx43 and Cx43CT attenuated the increase in FN induced by high glucose in GMCs, confirming the importance of Cx43 in renal fibrosis. The c-Src inhibitor PP2 also exhibited an inhibitory effect on the overexpression of ICAM-1, TGF- $\beta 1$ and FN induced by high glucose, thus confirming the role of $\mathrm{c}-\mathrm{Src}$ in the activation of NF-kB.

\section{Conclusions}

Our study describes a novel mechanism of NF- $\mathrm{kB}$ activation in high glucose-treated GMCs involving Cx43. In summary, downregulation of $\mathrm{Cx} 43$ induced by high glucose activates c-Src, which in turn promotes interaction between $\mathrm{c}-\mathrm{Src}$ and $\mathrm{I} \mathrm{KB}-\alpha$ and contributes to NF$\kappa \mathrm{B}$ activation, leading to renal inflammation. The results presented in this study show that Cx43 induces NF-kB activation and fibrosis in GMCs, which is beneficial for the development of new therapies against DN. However, the mechanism by which regulation of $\mathrm{Cx} 43$ expression occurs requires further study.

\section{Methods}

\section{Cell culture and transfection}

Rat GMCs were separated from the glomeruli of SpragueDawley (SD) rats and identified via a specific assay as previously described [44]. The cultured cells were used at confluence between the $5^{\text {th }}$ and $8^{\text {th }}$ passages. Confluent cells were rendered quiescent by incubation for $24 \mathrm{~h}$ in serum-free medium before treating with glucose (5.5 mmol/L as normal glucose and $30 \mathrm{mmol} / \mathrm{L}$ as high glucose) or osmotic control (mannitol, $30 \mathrm{mmol} / \mathrm{L}$ final concentration) for various times. $10 \mu \mathrm{M}$ PP2 (c-Src inhibitors) or $10 \mu \mathrm{M}$ PP3 (inactive analogue) were added before high glucose for $30 \mathrm{~min}$ (Sigma-Aldrich, St. Louis, MO). Transfection of GFP-Cx43, Flag-Cx43CT (Addgene, Cambridge, MA) and Cx43-siRNA plasmid (gift from Tao Liang professor, Zhongshan School of Medicine, SYSU, China) were performed per the manufacturer's instruction for Lipofectamine ${ }^{\mathrm{TM}}$ LTX \&Plus Reagent (Life Technologies, Carlsbad, CA).

\section{Immunoprecipitation and immunoblotting}

The cell monolayers were lysed in a cell lysis buffer for immunoprecipitation (Beyotime, Jiangsu, China). Immunoprecipitation was performed by incubating $0.5 \mathrm{mg}$ cell lysate protein which was determined by bicinchoninic acid assay (BCA) according to the manufacture's instructions (Thermo Fisher Scientific, Rockford, IL) with $1 \mu \mathrm{g}$ of corresponding antibody and protein G/A agarose bead (Merk, Darmstadt, Germany) at $4^{\circ} \mathrm{C}$ overnight. Immunoblotting was performed as previously described [45]. Kidney tissues were lysed, proteins were extracted as previously published [46]. The nuclear and cytoplasmic proteins of GMCs were extracted using a commercially available assay kit (Active Motif, Carlsbad, CA) and the total proteins were extracted as published [46]. The signals were visualized by a GE ImageQuant LAS4000mini, and analyzed using the Quantity One Protein Analysis Software (Bio-Rad Laboratories, Hercules, CA). The antibodies included mouse monoclonal antibodies against connexin43, NF- $\mathrm{kB}$ p65, Inhibitor of $\kappa \mathrm{B}-\alpha(\mathrm{I} \kappa \mathrm{B}-\alpha), \mathrm{p}-\mathrm{Tyr}$ and $\mathrm{FN}$, rabbit polyclonal antibody against $\mathrm{c}-\mathrm{Src}$, goat polyclonal anti-body against ICAM-1 and ZO-1 (Santa Cruz Biotechnology, Santa Cruz, CA), rabbit monoclonal antibodies against phospho-c-Src (Tyr), connexin43, phospho-IкB- $\alpha$ (Ser) and TGF- $\beta$ (Cell Signalling, Danvers, MA), rabbit monoclonal antibodies against Histone H1.4 and $\alpha$-tubulin (Sigma-Aldrich, St. Louis, MO), mouse monoclonal antibodies against Thy-1.1 and RECA-1 (Abcam, Cambridge, MA).

\section{Confocal laser scanning fluorescence microscopy (LSCM)}

Different groups of adherent cells were washed with phosphate-buffered saline (PBS), fixed with $4 \%$ paraformaldehyde in PBS for $20 \mathrm{~min}$, and permeabilized with $0.1 \%$ TritonX-100 for $5 \mathrm{~min}$ at room temperature. Cells 
were incubated with antibodies against NF-kB p65, connexin $43, \mathrm{c}-\mathrm{Src}, \mathrm{I \kappa B}-\alpha$ or $\mathrm{FN}$ overnight at $4^{\circ} \mathrm{C}$ after blocking with $10 \%$ goat serum. Or frozen kidney sections $(7.5 \mu \mathrm{m})$ were incubated with antibodies against Cx43, Thy-1.1 and RECA-1 overnight at $4^{\circ} \mathrm{C}$ after blocking with $10 \%$ goat serum. Then the cells and sections were incubated in the dark at room temperature for $1 \mathrm{~h}$ with a secondary antibody (Alexa Fluor ${ }^{\circ} 488$, Alexa Fluor ${ }^{\circ}$ 546, Invitrogen, Carlsbad, CA). The nucleus was stained with Hoechst33342. Cells and sections were placed under a laser scanning confocal microscope (LSM710, Carl Zeiss, Germany) for observation and image acquisition.

Assessment of gap junctional intercellular communication Gap junction permeability was determined by the scrapeloading/dye transfer technique [37]. Scrape-loading was performed by scraping the cell layer with a broken razor blade in culture media containing Lucifer yellow $(1 \mathrm{mg} /$ $\mathrm{ml}$, Life Technologies, Carlsbad, CA). Lucifer yellow is a low molecular weight $(457 \mathrm{Da})$ fluorescent dye that can pass through the gap junctions of loaded cells to their neighbors. After $2 \mathrm{~min}$, the dye solution was removed and the cells were carefully washed. Subsequently, 5 min after scraping, fluorescence photomicrographs were captured with a laser scanning confocal microscope (LSM710, Carl Zeiss, Germany). At least six photomicrographs of the centre of the dish were taken and the fluorescent area occupied by Lucifer yellow in the images was measured with the image-analyzer software (Scion Image, Scion Corporation, Frederick, MD).

\section{Animal experiment}

Male SD rats $(n=20,200 \pm 10 \mathrm{~g})$ were obtained from the Laboratory Animal Center, Sun Yat-sen University, Guangzhou, China Animal (Quality Certificate No.: 0005201). $d b / d b$ (male, $n=10,40 \pm 5 \mathrm{~g}$ ) mice were obtained from the model animal research center of Nanjing University (Quality Certificate No.: 0007963). All animal procedures conformed to the China Animal Welfare Legislation and were reviewed and approved by the Sun Yat-sen University Committee on Ethics in the Care and Use of Laboratory Animals. All animals were housed under standard conditions with free access to regular food and water. After feeding with regular diet for 1 week, STZ-diabetic rats were induced as previously reported [24]. Diabetic rats were confirmed by the levels of fasting blood glucose measurement ( $\geq 16.7 \mathrm{mmol} / \mathrm{l}$ after $72 \mathrm{~h}$ injection). It was continued for 12 weeks, after which the rats were sacrificed. $d b / d b$ mice were sacrificed at the time when they were 12 weeks age. Kidney samples were rapidly excised, weighed and frozen in liquid nitrogen and then stored at $-80^{\circ} \mathrm{C}$ or fixed in $10 \%$ neutral-buffered formalin.

\section{Immunohistochemistry}

Kidney sections $4 \mu \mathrm{m}$ thick were processed using a standard immunostaining protocol as previously reported [47]. A negative control was prepared by omitting the primary antibody.

\section{Statistical analysis}

All experiments were performed at least in triplicate. The data were assessed using SPSS 11.5. All values were expressed as mean \pm SD. Statistical analyses of data were performed by one-way ANOVA using post-hoc multiple comparisons. $P<0.05$ was considered to be statistically significant.

\section{Additional files}

Additional file 1: Figure S1. Half-life of Cx43 was explored in GMCs cultured in normal glucose or high glucose using cycloheximide. (A) GMCs cultured in normal glucose (5.5 mM) were co-incubated with $10 \mu \mathrm{M}$ cycloheximide for the indicated time. (B) GMCs cultured in high glucose $(30 \mathrm{mM})$ were co-incubated with $10 \mu \mathrm{M}$ cycloheximide for the indicated time. (C) GMCs were treated for 30 min with increasing concentrations of glucose as indicated. Then proteins were extracted for analysis of $\mathrm{C} \times 43$ by immunoblotting. $\mathrm{a}$-Tubulin was used as a loading control. ${ }^{*} P<0.05$ vs. control group. Chx, cycloheximide.

Additional file 2: Figure S2. HIF-1a is regulated in the GMCs by high glucose or low levels of $\mathrm{C} \times 43$. (A and $\mathbf{B}$ ) GMCs were treated with high glucose for the indicated time, then proteins were extracted for analysis of HIF-1a by immunoblotting. (C) GMCs were transfected with Cx43-siRNA in normal glucose $(5.5 \mathrm{mM})$ or GFP-Cx43 in high glucose (30 mM). After $48 \mathrm{~h}$, proteins were extracted for analysis of $\mathrm{C} \times 43$ and HIF-1a by immunoblotting. (D) GMCs cultured in high glucose were co-incubated with PP2 or PP3 $(10 \mu \mathrm{M})$ or PDTC $(100 \mu \mathrm{M})$. After $48 \mathrm{~h}$, proteins were extracted for analysis of HIF-1a by immunoblotting. a-Tubulin was used as a loading control. ${ }^{*} P<0.05$ vs. normal glucose-treated group. ${ }^{\sharp} P<0.05$ vs. high glucose-treated group.

\section{Abbreviations}

Cx43: Connexin43; Cx43CT: Carboxy tail of Cx43; DN: Diabetic nephropathy; ECM: Extracellular matrix; FN: Fibronectin; GJIC: Gap junctional intercellular communication; GMCs: Glomerular mesangial cells; ICAM-1: Intercellular adhesionmolecule-1; IKK: IKB kinase; IKB-a: Inhibitor of KB-a; NF-KB: Nuclear factor kappa-B; TGF- $\beta 1$ : Transforming growth factor-beta 1; SD rats: SpragueDawley rats.

\section{Competing interest}

The authors declare that there is no conflict of interest associated with this manuscript.

\section{Authors' contributions}

XX designed and performed experiments, acquisition and analysis of data, and drafted the manuscript. TL, XTC and KPH helped to perform experiments and prepare the manuscript. JH, SGW and CC have conceived of the study, participated in its design and coordination. $\mathrm{HQH}, \mathrm{PQL}$ and XYS have been involved in drafting the manuscript and revising it critically for important intellectual content. All authors have read and approved the final version of this manuscript.

\section{Acknowledgement}

This study was supported by research grants from the National Natural Science Foundation of China (No. 81170676), the Science, Technology Program of Guangdong province, PR China (No.2011A080502004) and National Natural Science Foundation of Guangdong province (No. S2012020010991). The authors appreciate Dr. Liang Tao (Zhongshan School of Medicine, SYSU, China) for providing Cx43-siRNA plasmid. 


\section{Author details}

${ }^{1}$ Laboratory of Pharmacology \& Toxicology, School of Pharmaceutical Sciences, Sun Yat-sen University, Guangzhou 510006, China. ${ }^{2}$ Department of Pharmaceutical Engineering, Ocean College, Hainan University, Haikou 570228, China. ${ }^{3}$ Vascular Biology Institute, Guangdong Pharmaceutical University, Guangzhou 510006, China.

Received: 8 January 2013 Accepted: 10 May 2013

Published: 29 May 2013

\section{References}

1. Mason RM, Wahab NA: Extracellular matrix metabolism in diabetic nephropathy. J Am Soc Nephrol 2003, 14:1358-1373.

2. Mariappan MM: Signaling mechanisms in the regulation of renal matrix metabolism in diabetes. Exp Diabetes Res 2012, 2012:749812.

3. Tuttle KR: Linking metabolism and immunology: diabetic nephropathy is an inflammatory disease. J Am Soc Nephrol 2005, 16:1537-1538.

4. Navarro-Gonzalez JF, Mora-Fernandez C, de Fuentes MM, Garcia-Perez J: Inflammatory molecules and pathways in the pathogenesis of diabetic nephropathy. Nat Rev Nephrol 2011, 7:327-340.

5. Bondar IA, Klimontov W, Nadeev AP: Urinary excretion of proinflammatory cytokines and transforming growth factor beta at early stages of diabetic nephropathy. Ter Arkh 2008, 80:52-56

6. Iwamoto M, Mizuiri S, Arita M, Hemmi H: Nuclear factor-kappa B activation in diabetic rat kidney: evidence for involvement of P-selectin in diabetic nephropathy. Tohoku J Exp Med 2005, 206:163-171.

7. Mezzano S, Aros C, Droguett A, Burgos ME, Ardiles L, Flores C, Schneider H, Ruiz-Ortega M, Egido J: NF-kappa B activation and overexpression of regulated genes in human diabetic nephropathy. Nephrol Dial Transplant 2004, 19:2505-2512

8. Herve JC, Bourmeyster N, Sarrouilhe D, Duffy HS: Gap junctional complexes: from partners to functions. Prog Biophys Mol Biol 2007, 94:29-65.

9. Evans WH, Martin PE: Gap junctions: structure and function (Review). Mo Membr Biol 2002, 19:121-136

10. Yao J, Zhu Y, Morioka T, Oite T, Kitamura M: Pathophysiological roles of gap junction in glomerular mesangial cells. J Membr Biol 2007, 217:123-130.

11. Zhang X, Chen X, Wu D, Liu W, Wang J, Feng Z, Cai G, Fu B, Hong Q, Du J: Downregulation of connexin 43 expression by high glucose induces senescence in glomerular mesangial cells. J Am Soc Nephrol 2006, 17:1532-1542

12. Sawai K, Mukoyama M, Mori K, Yokoi H, Koshikawa M, Yoshioka T, Takeda R, Sugawara A, Kuwahara T, Saleem MA, et al: Redistribution of connexin43 expression in glomerular podocytes predicts poor renal prognosis in patients with type 2 diabetes and overt nephropathy. Nephrol Dial Transplant 2006, 21:2472-2477.

13. Takenaka T, Inoue T, Okada H, Ohno Y, Miyazaki T, Chaston DJ, Hill CE, Suzuki H: Altered gap junctional communication and renal haemodynamics in Zucker fatty rat model of type 2 diabetes. Diabetologia 2011, 54:2192-2201.

14. Liu L, Hu X, Cai GY, Lv Y, Zhuo L, Gao JJ, Cui SY, Feng Z, Fu B, Chen XM: High glucose-induced hypertrophy of mesangial cells is reversed by connexin43 overexpression via PTEN/Akt/mTOR signaling. Nephrol Dial Transplant 2012, 27:90-100.

15. Giepmans BN: Role of connexin43-interacting proteins at gap junctions. Adv Cardiol 2006, 42:41-56.

16. Giepmans BN, Hengeveld T, Postma FR, Moolenaar WH: Interaction of c-Src with gap junction protein connexin-43: role in the regulation of cell-cell communication. J Biol Chem 2001, 276:8544-8549.

17. Gilleron J, Fiorini C, Carette D, Avondet C, Falk MM, Segretain D, Pointis G: Molecular reorganization of $\mathrm{Cx} 43, \mathrm{Zo}-1$ and Src complexes during the endocytosis of gap junction plaques in response to a non-genomic carcinogen. J Cell Sci 2008, 121:4069-4078.

18. Suzaki Y, Yoshizumi M, Kagami S, Nishiyama A, Ozawa Y, Kyaw M, Izawa Y, Kanematsu Y, Tsuchiya K, Tamaki T: BMK1 is activated in glomeruli of diabetic rats and in mesangial cells by high glucose conditions. Kidney Int 2004, 65:1749-1760.

19. Mima A, Abe H, Nagai K, Arai H, Matsubara T, Araki M, Torikoshi $K$, Tominaga T, lehara N, Fukatsu A, et al: Activation of Src mediates PDGF-induced Smad1 phosphorylation and contributes to the progression of glomerulosclerosis in glomerulonephritis. PLoS One 2011, 6:e17929.
20. Alonso F, Krattinger N, Mazzolai L, Simon A, Waeber G, Meda P, Haefliger JA: An angiotensin II- and NF-kappa B-dependent mechanism increases connexin 43 in murine arteries targeted by renin-dependent hypertension. Cardiovasc Res 2010, 87:166-176.

21. Zhao Y, Rivieccio MA, Lutz S, Scemes E, Brosnan CF: The TLR3 ligand polyl : $C$ downregulates connexin43 expression and function in astrocytes by a mechanism involving the NF-kappa B and P13 kinase pathways. Glia 2006, 54:775-785.

22. Huang WC, Chen JJ, Chen CC: C-Src-dependent tyrosine phosphorylation of IKK beta is involved in tumor necrosis factor-alpha-induced intercellular adhesion molecule-1 expression. J Biol Chem 2003, 278:9944-9952.

23. Fan CG, Li Q, Ross D, Engelhardt JF: Tyrosine phosphorylation of I kappa B alpha activates NF kappa B through a redox-regulated and c-Src -dependent mechanism following hypoxia/reoxygenation. J Biol Chem 2003, 278:2072-2080.

24. Xie X, Peng J, Huang K, Huang J, Shen X, Liu P, Huang H: Polydatin ameliorates experimental diabetes-induced fibronectin through inhibiting the activation of NF-kappaB signaling pathway in rat glomerular mesangial cells. Mol Cell Endocrinol 2012, 362:183-193.

25. Singh D, Solan JL, Taffet SM, Javier R, Lampe PD: Connexin 43 interacts with zona occludens- 1 and -2 proteins in a cell cycle stage-specific manner. J Biol Chem 2005, 280:30416-30421

26. Chow FY, Nikolic-Paterson DJ, Ozols E, Atkins RC, Tesch GH: Intercellular adhesion molecule-1 deficiency is protective against nephropathy in type 2 diabetic db/db mice. J Am Soc Nephrol 2005, 16:1711-1722

27. Okada S, Shikata K, Matsuda M, Ogawa D, Usui H, Kido Y, Nagase R, Wada J, Shikata $Y$, Makino $\mathrm{H}$ : Intercellular adhesion molecule-1-deficient mice are resistant against renal injury after induction of diabetes. Diabetes 2003, 52:2586-2593

28. Sharma K, Jin Y, Guo J, Ziyadeh FN: Neutralization of TGF-beta by anti-TGF -beta antibody attenuates kidney hypertrophy and the enhanced extracellular matrix gene expression in STZ-induced diabetic mice. Diabetes 1996, 45:522-530.

29. Murphy M, Docherty NG, Griffin B, Howlin J, McArdle E, McMahon R, Schmid $H$, Kretzler M, Droguett A, Mezzano S, et al: IHG-1 amplifies TGF-beta1 signaling and is increased in renal fibrosis. J Am Soc Nephrol 2008 , 19:1672-1680.

30. Wang A, Ziyadeh FN, Lee EY, Pyagay PE, Sung SH, Sheardown SA, Laping NJ, Chen S: Interference with TGF-beta signaling by Smad3-knockout in mice limits diabetic glomerulosclerosis without affecting albuminuria. Am J Physiol Renal Physiol 2007, 293:F1657-1665.

31. Musil LS, Goodenough DA: Biochemical analysis of connexin43 intracellular transport, phosphorylation, and assembly into gap junctional plaques. J Cell Biol 1991, 115:1357-1374.

32. Laird DW, Puranam KL, Revel JP: Turnover and phosphorylation dynamics of connexin43 gap junction protein in cultured cardiac myocytes. Biochem J 1991, 273(Pt 1):67-72.

33. Laird DW, Castillo M, Kasprzak L: Gap junction turnover, intracellular trafficking, and phosphorylation of connexin43 in brefeldin A-treated rat mammary tumor cells. J Cell Biol 1995, 131:1193-1203.

34. Schaeffer G, Levak-Frank S, Spitaler MM, Fleischhacker E, Esenabhalu VE, Wagner AH, Hecker M, Graier WF: Intercellular signalling within vascular cells under high D-glucose involves free radical-triggered tyrosine kinase activation. Diabetologia 2003, 46:773-783.

35. Huang Q, Sheibani N: High glucose promotes retinal endothelial cell migration through activation of Src, PI3K/Akt1/eNOS, and ERKs. Am J Physiol Cell Physiol 2008, 295:C1647-1657.

36. Lau AF: c-Src: bridging the gap between phosphorylation- and acidification-induced gap junction channel closure. SCi STKE 2005, 2005: pe33.

37. Gangoso E, Herrero-Gonzalez S, Giaume C, Naus C, Medina JM, Tabernero A: Connexin43 inhibits the oncogenic activity of c-Src in C6 glioma cells. FEBS J 2011, 278:456-456

38. Valle-Casuso JC, Gonzalez-Sanchez A, Medina JM, Tabernero A: HIF-1 and c-Src mediate increased glucose uptake induced by endothelin-1 and Connexin43 in astrocytes. PLOS One 2012, 7:e32448.

39. Kumar A, Takada Y, Boriek AM, Aggarwal BB: Nuclear factor-kappa B: its role in health and disease. Journal of Molecular Medicine-Jmm 2004, 82:434-448.

40. Bui NT, Livolsi A, Peyron JF, Prehn JHM: Activation of nuclear factor kappa $B$ and bcl-x survival gene expression by nerve growth factor requires tyrosine phosphorylation of I kappa B alpha. J Cell Biol 2001, 152:753-763. 
41. Bunting K, Rao S, Hardy K, Woltring D, Denyer GS, Wang J, Gerondakis S, Shannon MF: Genome-wide analysis of gene expression in T cells to identify targets of the NF-kappa B transcription factor c-Rel. J Immunol 2007, 178:7097-7109.

42. Koval M, Billaud M, Straub AC, Johnstone SR, Zarbock A, Duling BR, Isakson $B E$ : Spontaneous lung dysfunction and fibrosis in mice lacking connexin 40 and endothelial cell connexin 43. Am J Pathol 2011, 178:2536-2546.

43. Jansen $J A$, van Veen $T A$, de Jong $S$, van der Nagel R, Driessen HE, Labzowski RP, Bosch AA, Oefner CM, Vos MA, de Bakker JM, van Rijen HV: Reduced Cx43 expression leads to increased fibrosis and Pro-arrhythmia due to enhanced fibroblast activity in aged and pressure overloaded mice. Circulation 2010, 122:A19348.

44. Geoffroy K, Wiernsperger N, Lagarde M, El Bawab S: Bimodal effect of advanced glycation end products on mesangial cell proliferation is mediated by neutral ceramidase regulation and endogenous sphingolipids. J Biol Chem 2004, 279:34343-34352.

45. Jiang Q, Liu PQ, Wu XQ, Liu WH, Shen XY, Lan TA, Xu SW, Peng J, Xie X, Huang HQ: Berberine attenuates lipopolysaccharide-induced extracelluar matrix accumulation and inflammation in rat mesangial cells: Involvement of NF-kappa B signaling pathway. Mol Cell Endocrinol 2011, 331:34-40.

46. Liu WH, Zhang XY, Liu PQ, Shen XY, Lan TA, Li WY, Jiang Q, Xie X, Huang HQ: Effects of berberine on matrix accumulation and NF-kappa B signal pathway in alloxan-induced diabetic mice with renal injury. Eur $J$ Pharmacol 2010, 638:150-155.

47. Lan T, Shen X, Liu P, Liu W, Xu S, Xie X, Jiang Q, Li W, Huang H: Berberine ameliorates renal injury in diabetic C57BL/6 mice: involvement of suppression of SphK-S1P signaling pathway. Arch Biochem Biophys 2010, 502:112-120.

doi:10.1186/1478-811X-11-38

Cite this article as: Xie et al:: Connexin43 mediates NF-KB signalling activation induced by high glucose in GMCs: involvement of c-Src. Cell Communication and Signaling 2013 11:38.

\section{Submit your next manuscript to BioMed Central and take full advantage of:}

- Convenient online submission

- Thorough peer review

- No space constraints or color figure charges

- Immediate publication on acceptance

- Inclusion in PubMed, CAS, Scopus and Google Scholar

- Research which is freely available for redistribution 